AN ONLINE DISCONNECT: A CASE STUDY OF THE EFFECT OF SOCIAL MEDIA ON A METROPOLITAN NEWSROOM'S ORGANIZATIONAL CULTURE

A Thesis
presented to
the Faculty of the Graduate School
at the University of Missouri-Columbia
In Partial Fulfillment
of the Requirements for the Degree
Master of Arts
CHARLES MINSHEW
Dr. Earnest Perry, Thesis Supervisor
JULY 2013


The undersigned, appointed by the dean of the Graduate School, have examined the thesis entitled

AN ONLINE DISCONNECT: A CASE STUDY OF THE EFFECT OF SOCIAL MEDIA ON A METROPOLITAN NEWSROOM'S ORGANIZATIONAL CULTURE

presented by Charles Minshew,

a candidate for the degree of Master of Arts,

and hereby certify that, in their opinion, it is worthy of acceptance.

Associate Professor Earnest Perry

Assistant Professor Amy Simons

Professor Lynda Kraxberger

Professor Michael Diamond 


\section{DEDICATION}

Most importantly, this thesis is dedicated to the memory of two very important people in my life that passed away while I pursued my Master's degree: my greatgrandfather Charles Mitchell and my grandfather Emory Luke. Both men instilled in me the importance of education; both pushed me to continue working hard in the midst of their own struggles.

This thesis is also dedicated to my parents, Roger and Janet Minshew, my brother Richard, as well as my grandparents, Charlie Mae Luke and Annette Minshew, and other extended family members who have listened to me talk about my research and who have supported me. They have shared my struggles, and they deserve to share in this success.

Finally, I never would have thought of the role of social media in the newsroom had it not been for the online producers, reporters, and editors at The Denver Post while I was an intern there. Thank you for working diligently for the community even on the darkest of days. 


\section{ACKNOWLEDGEMENTS}

When I began formulating the idea of studying the effect of social media use on newsroom culture, I didn't know where to turn in searching for an advisor. I thank Dr. Earnest Perry for agreeing to listen to my research pitch in late 2012 and for serving as my committee chair. His guidance, assurance, and editing are greatly appreciated.

Amy Simons and Lynda Kraxberger have influenced my interest in convergence journalism since I took Convergence Reporting in Spring 2012. In their courses, I was taught to tell a complete and compelling story that matters. Those lessons guided me as I wrote this thesis. Amy and Lynda, along with Karen Mitchell, have prepared me well for the challenges I will face in the "real world."

Thank you to Dr. Michael Diamond, director of the University's Center for the Study of Organizational Change for serving as the second reader for this thesis. His insight on organizational culture was invaluable for this research. 


\section{TABLE OF CONTENTS}

ACKNOWLEDGEMENTS

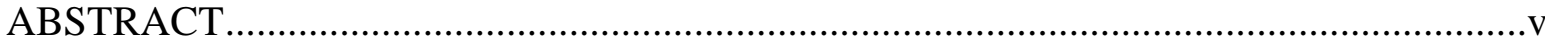

Chapter

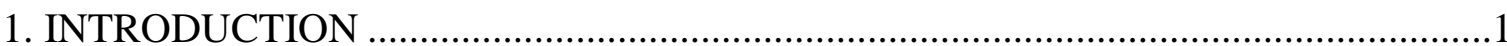

Preface

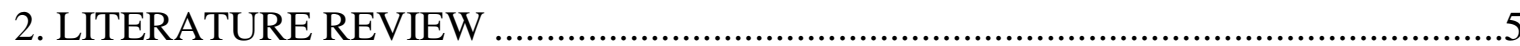

Organizational Culture in Newsrooms...................................................................5

Newsroom Organizational Change ...................................................................

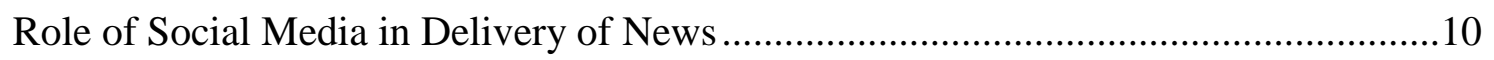

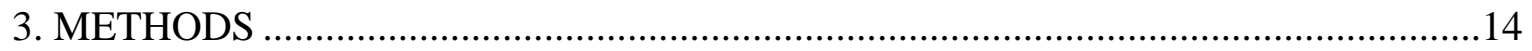

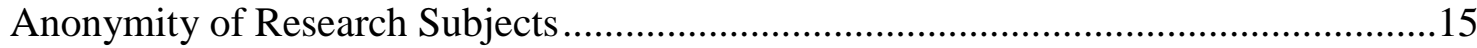

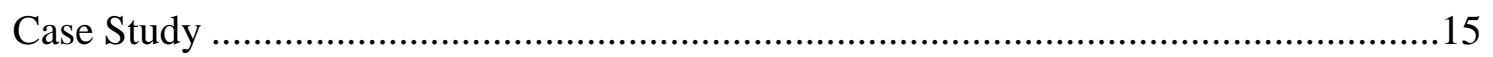

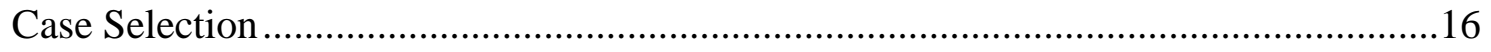

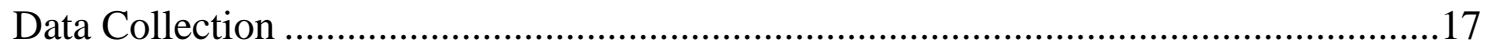

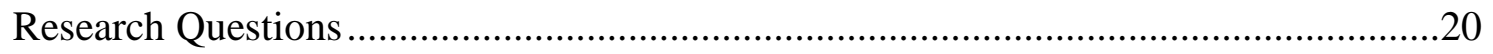

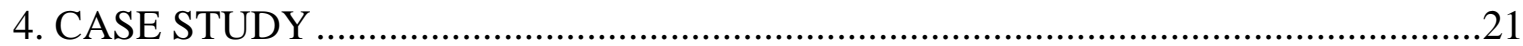

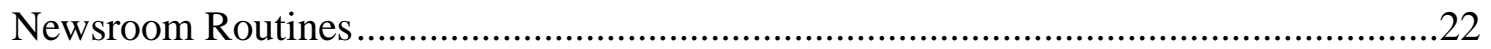


History of Social Media at The Post......

Typical Day for the Social Media Editor

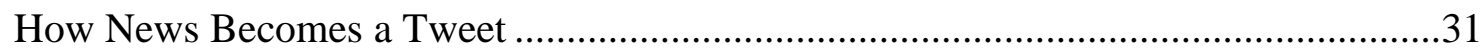

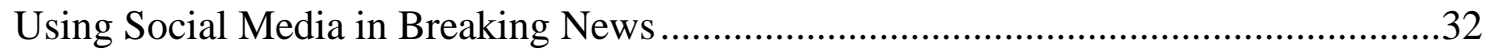

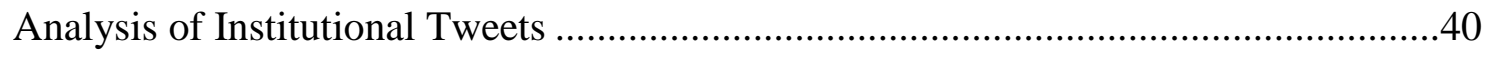

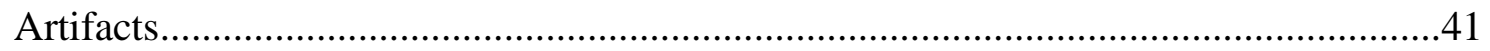

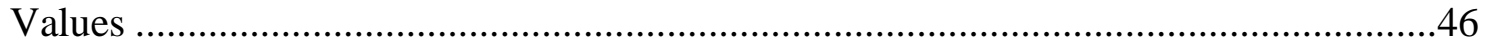

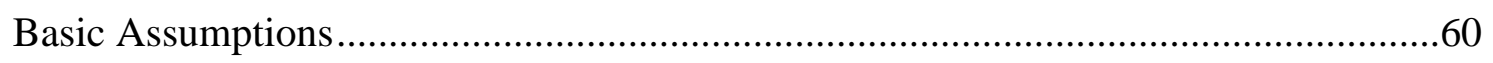

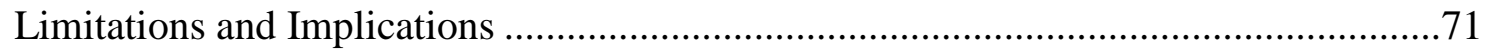

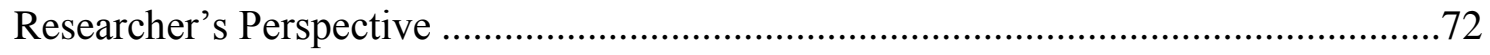

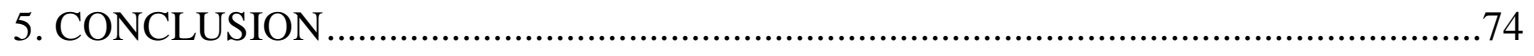

APPENDIX

1. ORGANIZATIONAL CHART, THE METROPOLITAN POST ...............................79

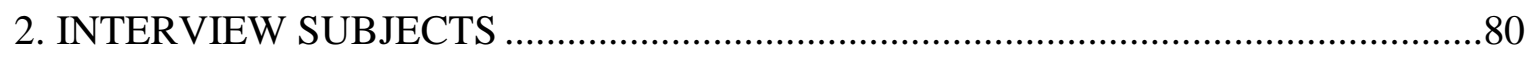

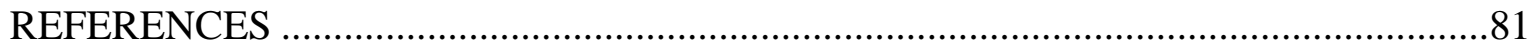




\title{
AN ONLINE DISCONNECT: A CASE STUDY OF THE EFFECT OF SOCIAL MEDIA ON A METROPOLITAN NEWSROOM'S ORGANIZATIONAL CULTURE
}

\author{
Charles Minshew \\ Dr. Earnest Perry, Thesis Supervisor
}

\begin{abstract}
This research explores the role of social media use in a traditional newsroom by examining how reporters and editors use social media tools, particularly Twitter and Facebook, in their day-to-day work activities. It uses the theoretical framework of organizational culture to understand how social media is used in story generation, source development, and promotion of news stories.

The researcher used a case study consisting of nearly four weeks of newsroom observations, nineteen interviews, and the analysis of more than 400 tweets from The Metropolitan Post, a newspaper in the American Midwest, to understand how the newsroom's culture was changing as a result of social media use. The research identified that the culture of this particular newsroom was not changing due to lack of leadership, communication, and a clear understanding of how to use social media.
\end{abstract}




\section{Introduction}

The definition of traditional newsrooms is quickly changing in the United States. For more than a century, newspapers relied on advertising in print-only endeavors. During the past decade, America's newsrooms have undergone drastic changes. With falling advertising revenues, publishers are searching for new funding sources. Editors are looking to digital tools to discover new ways to tell stories and to interact with readers. Specifically, social media has provided an opportunity for editors and reporters to gather story ideas, to interact with news consumers, and to publicize their content online. But, how are newsrooms in the United States using these tools? In the literature review, I take a look at how newspapers and other media companies in the United States are using social media in a variety of ways. Later, in a case study, I examine one newsroom's struggle to figure out how to best use social media to their advantage.

\section{Preface}

Many - if not all - of my views on the role of social media in a newsroom setting were shaped by the time I spent in The Denver Post newsroom in the summer of 2012. During that time, we worked on two major national news events. The first was continuing coverage of wildfires that destroyed almost 650 homes in Colorado. The second was coverage of the Aurora Theater shooting where a gunman killed 12 people and injured 58.

As an intern through the Dow Jones News Fund, I was a web producer with The Denver Post. I worked extensively with social media, using it to update readers on a regular basis throughout the day and occasionally used it to get in touch with witnesses to 
events like the Aurora Theater shooting. I found witnesses on Twitter and Reddit. After collecting their stories, I forwarded the information to editors in the newsroom.

In 2013, The Denver Post won a Pulitzer Prize for Breaking News Coverage for its coverage of the theater shooting in Aurora. Specifically, in its citation, the Board noted the staff's use of social media, along with other tools to "capture a breaking story and provide context" (Pulitzer 2013). I contributed to this award through the creation of an interactive timeline alongside fellow web producer Daniel Schneider. The staff was also a finalist in the same category for their coverage of the wildfires in Colorado.

This was only the second time that the Pulitzer Board awarded a prize in the Breaking News category to a newspaper for the use of social media during news coverage. The first time was in 2012, when the Tuscaloosa News received the award for their extensive use of Twitter during tornadoes that killed more than 60 people and forced the staff to print the paper 50 miles away.

Throughout the observation phase of the research, I constantly found myself comparing the work of The Metropolitan Post - this is a pseudonym for a newspaper based in the American Midwest - to that of The Denver Post. I found that there were many differences between the two newspapers, especially in management structure for social media use and in the attitude by staff members toward social media use.

In the case of The Denver Post, a social media editor on the staff helped set the policy of social media use for the newspaper and coordinated an effort to increase the number of people on staff that had a social media presence. In comparison, The Metropolitan Post also employs a social media editor. During the observation period, I found the two roles to be different, despite the use of the same title. 
On the newspaper's Twitter directory page on the DenverPost.com website, there are a total of 288 institutional and staff member accounts. As the case study indicates, the newspaper in this research project boasts only 54 accounts in the only official list. To provide a fair comparison of the two newspapers' subscriber base, it should also be noted that The Denver Post is 13th in daily print circulation and The Metropolitan Post's print circulation is much smaller. (Alliance for Audited Media 2013).

Additionally, the social media editor for The Denver Post also works as an engagement editor with the newspaper's corporate parent, Digital First Media. There is no such relationship between The Metropolitan Post and its parent company. In fact, the newspaper has been waiting for social media guidance from the corporate parent for nearly two years now.

The purpose of this study is to understand the effect of social media on newsroom organization and news distribution in traditionally print newsrooms in the United States. Understanding the impact of social media on newsrooms is important since it could change the way news organizations deliver content to consumers. In particular, the research explores how social media changes the interaction between reporters, editors, and managers inside the newsroom as well as sources outside of the newsroom. Also explored is the way social media is used to distribute stories produced in the newsroom. Specifically, this research explores the relationship between social media use by reporters and editors and how the use of these tools affects the creation and distribution of stories. This research expands existing knowledge on the culture of change in newsrooms by examining how social media changes the values of reporters and editors at one newspaper. It also expands the current understanding of how technology is a catalyst 
for change in traditional newsrooms in the United States. For the purposes of this research, a "traditional" newsroom is one that produces a daily, printed newspaper as its flagship product. 


\section{Literature Review}

To study the effect of social media use on newsroom hierarchy, understanding what organizational culture and hierarchy are and how they have been applied to newsrooms in previous research is important. Also crucial is a presentation of traditional newsroom organization to understand changes. To explore previous research on the role of social media in the delivery of information to readers is also pertinent. Specifically, the role of social media in the delivery of news is addressed in this literature review.

\section{Organizational Culture in Newsrooms}

Schein defined culture, when used to refer to a group, as:

A pattern of shared basic assumptions that the group has learned as it solved its problems of external adaptation and internal integration, that has worked well enough to be considered valid, and therefore, to be taught to new members as the correct way to perceive, think, and feel in relation to those problems (Schein 2010a, p. 18).

Schein identifies three levels of culture that are also useful in the definition of an organization's culture. The first level consists of artifacts that include observed behavior and visible structures. The next level includes an organization's beliefs and values, particularly ideologies, goals and rationalizations. The third stage includes basic underlying assumptions that consist of taken-for-granted beliefs that determine an individual's behavior, perception and thoughts (2010a, 24).

In the newsroom studied in this research, artifacts include the interaction between staff members, the newsroom, and the computer systems used for many tasks, including 
publishing to the website and social media. The beliefs and values include the staff members' beliefs on social media, which vary throughout the newsroom. The underlying assumptions include those that staff members have about the motives of others including editors - when it comes to promoting or distancing themselves from social media use in the newsroom.

As with many forms of mass media, the relationship between the newspaper and news consumer has been one based on one-way communication. The newspaper "broadcasts" the news to the reader and that is the extent of the interaction between the two entities (Pavlik, 2000, 234). Internally, the typical flow of news might be seen like this: A source provides a reporter with information for a potential story. The reporter might have a discussion about the idea and — if accepted by the editor - ultimately hands off the story to an editor. After editing, the editor sends the story on for placement in the print edition and for online posting. A reader then reads the story.

In this relationship, editors have a great deal of power since they are the last to make changes to a story before it goes to print. Editors began to find more responsibility in the 1980's after electronic editing systems were introduced, resulting in "a new layer of stresses for the editor and the staff" of a traditional newsroom (Giles 1987, 469). While the power has shifted from some obsolete positions, such as typesetters, all influence does not start with an editor. In a national survey, editors have a "relatively high level" of influence on news organizations, but they understand some of the power comes from newspaper investors (Gade 2008, 379). Reporters typically do not have much influence in newsroom operations decisions. 
In the late 1990's, journalists at the St. Louis Post-Dispatch saw structural changes in the newsroom as a positive development if the changes improved the quality of the journalism. By 2000, these same journalists "perceived their news values were changing" to support public journalism but they still "held some reservations" on making changes to the way they reported stories out of fear of losing their own authority on the job (Gade and Perry 2003, 337). One of the main worries of the reporters was the ability to pitch and report on stories they wanted to cover.

It was also difficult for readers to become a part of the newsroom conversation in the 1980's and 1990's. According to a national survey of reporters and editors, approximately 50 percent of journalists in the late 1980's were "insulated from their public" (Giles 1987, p. 269). Ten years later, one of the biggest challenges was being able to get in touch with reporters who wrote the stories. A national survey showed that 67 percent of newspapers in the United States did not publicly provide e-mail addresses for reporters on their online stories (Schultz 1999).

\section{Newsroom Organization Change}

The one thing that has a significant impact on a newsroom --- or any organization for that matter - is change. The biggest change for traditional print newsrooms in the past decade has been the introduction of digital technologies. However, digital changes started long before people began talking about the Internet and social media. These technologies have challenged the traditional structure of large-circulation newspapers across the country, forcing some newspapers to cease their print operations in favor of online-only publications. Others have closed their doors completely. 
As early as the 1990's, media scholars have explored ways that technology changes journalism. In 1999, The Orem Daily Journal became the first daily newspaper to cease printing in favor of an online-only format. Publisher Levor Oldham told the Associated Press that the move was driven by "common sense," noting "the future of newspapers is on the Web" (Associated Press, 1999). A visit to the website, http://www.ucjournal.com, no longer points to the newspaper, but instead to what appears to be a blog about German tourism. It seems that while the future of newspapers might have been on the Web, it was not exactly right for The Orem Daily Journal.

In 2009, The Seattle Post-Intelligencer moved to an online-only format while the Rocky Mountain News in Denver, Colorado was closed by parent company, E.W. Scripps. On December 4, 2008, the day of the announcement that the Rocky Mountain News was being sold, the company's president and CEO Rich Boehne told the newspaper's staff, "You're the model of what a newspaper's going to need to look like in the future. We would have never, never considered this if the environment was a little bit different" (Roberts, 2009).

Two months later, the Rocky Mountain News printed its final edition. Economic conditions and declining advertising sales were contributing factors to the closure. Exactly what happened? Current research shows that for every dollar gained in digital revenue, \$7 are lost in print revenue (Rosenstiel, Jurkowitz \& Ji 2012). The same researchers found that newsroom staff members who are "more aligned with the legacy tradition" are challenging the changing business models. When newsroom structures change, a reporter's job satisfaction does not decrease unless the change in policy benefits the business side of the newsroom operation (Stamm and Underwood 1993, p. 
535). In the case of the Rocky Mountain News, job satisfaction could not be measured since everyone who worked for that publication instantly found themselves out of a job.

Job satisfaction can possibly be directly linked to changes in the newsroom. Giles explains that "technostress" occurs when staff members are attempting to adapt to new technologies in the newsroom (1987, p. 469). The author also suggests that editors and publishers have to avoid the phenomenon of "pushing into the background the needs and frustrations of the people using the new technology" (Giles 1987, p. 470).

With new technology comes a change in a newsroom's organization at many levels - including physically. Gade discusses that the "challenge of change" in a newsroom is "getting rank-and-file to accept the core values that embody management's vision for a transformed newsroom culture (2004, p. 40). Robinson observed an unnamed "hybrid" newsroom that shifted to a digital-only platform in 2008. During her observation, the newspaper's online editor protested a move that would have placed his department in the center of the newsroom, saying, "We like where we are because it is out of the way" (2011, p. 1128). She reported that all staff members saw changes in their social relationships because of the physical move (Robinson 2011, p. 1129).

In some cases, a shifting newsroom culture does not consist of a shift from printfirst to web-first, but instead a converging of resources. In one case, the culture changed when a newspaper, website, and television station moved to one newsroom in Tampa, Florida, in March 2000. One of the researchers' major findings was that reporters and photographers found themselves with too much work to do and not enough time to finish it all. Some of the staff members told researchers that they felt their managers did not 
understand the work required to produce stories across three platforms (Dupagne and Garrison 2006, p. 247).

As evidenced by the literature, change in newsrooms is a constant occurrence. However, the times are changing as well. New times have brought a whole new world of changes to traditional media. Chief among the recent changes to newsrooms is the use of social media by reporters, editors, and in some cases, the news organization's management team.

\section{Role of Social Media in Delivery of News}

Social media is changing the way that newsrooms interact with news consumers. Balancing the role of interacting with the public and maintaining day-to-day operations has posed a challenge to newspaper editors. As Deuze concludes, journalists "talk about the importance of being interactive without accepting the fact that ongoing levels of interactivity undermine the 'we write, you read' dogma of modern journalism" (2003, p. 220).

Newspaper editors and reporters have begun to use social media as a way to connect with their readers by posting content to social media. The frequency of posting on social media has been on the rise. Of those newspapers that utilize Twitter, more than 70 percent post to the microblogging site on a daily basis (Greer and Yan 2011). A quick scan of a newspaper's Twitter feed will probably yield headlines most of the time. However, some organizations are using Twitter to provide short, information-rich updates to readers.

These short updates allow readers to be constantly connected to their news sources. When using Twitter in a way that allows news consumers to "maintain a mental 
model of news and events around them," the social media service acts as an awareness system. Awareness systems allow multiple people and organizations to be connected, regardless of location. (Hermida 2010, p. 301).

Hermida also suggests that Twitter is not only a tool for the quick delivery of breaking news. He writes that it is also a tool that journalists can use to discover trends in news that they otherwise would not have seen (Hermida 2010, p. 302). When used as a breaking news tool, Hermida suggests that the goal is to inform instead of becoming a burden to the consumer (2012, p. 303). One way to facilitate a search on Twitter is to use hashtags. Hashtags (\#) are a popular form of tagging posts on Twitter with a searchable term that makes common tweets easier to find. During the aftermath of the theater shooting in Aurora, Colorado on July 20, 2012, media outlets and readers began using the hashtag \#theatershooting to share information and stories about the shooting. The newspaper's social media editor, Dan Petty said that while the hashtag was useful for publicizing their stories, the search feature was overwhelmed when thousands of people used the hashtag for posts (Buttry 2012).

As news organizations grow and evolve to keep up with the latest technologies, many may find the need to change or begin to formalize the policies for interacting with the public via social media. A formal policy is extremely important since reporters and photographers can sometimes disregard the wishes of their employer from time to time when using social media. During the rallies surrounding Occupy Wall Street, the Associated Press reprimanded their photographer for "tweeting too quickly" about the rally in Manhattan (Huffington Post 2011). The pushback from the Associated Press can likely be due to the company's business model, which relies on photos and stories 
moving across the wire service that many publications across the world use on a daily basis.

Farhi (2009) recounts the story of Washington Post book critic Ron Charles, who tweeted a rumor about New Yorker magazine changing their publication schedule. He raises the question of what would happen should a reporter become entangled in a lawsuit over a tweet. "Would the tweeter's employee be as culpable as the tweeter, given the tweets, arguably, are an extension of the journalist's work?" (Farhi 2009, p. 31). A month after the incident, the Washington Post began considering a social media policy for their reporters.

In addition to sharing stories on social media websites, newspapers are also seeing their agendas set by external, digital news organizations. Particularly, blogs have been successful at "setting traditional media's online news agenda (Meraz 2011, p. 187). At The Guardian, a newspaper in the United Kingdom, Twitter is "used as a collaborative research tool by editors and journalists working on stories and blogs, both for ideas and to provide evidence for all branches of news" (Ahmad 2010, p. 150).

Social media also provides an opportunity to deliver the news faster than ever before. On Facebook and Twitter, it is easy to find large media organizations like the Associated Press along with small newspapers in rural communities. Many use social media services like Twitter to provide followers with links to stories and updates on breaking news situations. Newspapers are not the only groups using social media to engage with their readers. A nationwide survey of television news organizations found that 98 percent of stations use, and 97 percent use Twitter as news-gathering tools (Lysak, Cremedas, and Wolf 2012, p. 193). 
Researchers at the Georgia Institute of Technology found that sources on Twitter were the first to break the news of Osama bin Laden's death in May 2011 but determined that many people still waited for traditional mass media sources, particularly on television, to confirm the news. (Hu et al 2012). 


\section{Methods}

Social media is just one of the latest tools to find its way into newsrooms across the world. As a result, reporters, editors, and administrators have to determine the best practices for using social media on a day-to-day basis. Mark Briggs compares the rise of popularity of social media in the newsroom to the advent of e-mail in the late 20th century and the introduction of the telephone. He writes that, when it comes to ethics, he sees no point in a social media ethics policy, noting that policy addendums were not popular for e-mail and telephone (Briggs 2013, p. 282).

How does social media change the distribution of news? How do staff members react to new technology in their daily lives? Giles writes that it is normal for staff members to be concerned about change due to new technology because people perceive it as a threat (1987, p. 370). He goes on to suggest that understanding individual perception to change is the best way to address changes in the newsroom.

This research is rooted in an extensive case study of The Metropolitan Post's dayto-day operations. The research design and decision to use a case study to determine how social media use affects the culture of the newsroom relies heavily upon previous research in hopes of building on it. Mayer conducted a case study of a Connecticut newspaper, The Register Citizen, to explore how the staff's use of audience engagement changed the newsroom's culture. While Mayer's study did not focus specifically on the use of social media tools, her use of Schein's three levels of analysis applies well to the case of The Metropolitan Post. To that end, this case study builds upon her previous research of a newsroom with what she called "extreme engagement efforts" (Mayer 2012, 
p. 46) by studying a newsroom that is still trying to figure out the best way to engage with readers using social media tools online.

This was accomplished through extended visits to the newsroom. For fourteen days, I spent more than eight hours per day observing staff members and attending meetings to understand the culture of news gathering. I was also present for the coverage of a major breaking news story after normal business hours and during planned coverage of President Barack Obama's State of the Union address.

The observations are paired with interviews with 19 staff members that represent a variety of roles and departments in the newsroom as well as a variety of opinions on the role of social media in the newsroom.

\section{Anonymity of Research Subjects}

Anonymity was promised to the newspaper and the staff members who participated in this research. In the case study, the organization's identity is veiled as The Metropolitan Post. To preserve the flow of the narrative and to prevent confusion when there are multiple staff members with similar titles, first name pseudonyms are used. Furthermore, interview subjects were provided with copies of an informed consent form but were not required to sign it, preventing any individual from being linked to the research.

\section{Case Study}

Case studies are intended to "expand and generalize theories," and do not represent an entire population (Yin 2009, 15). Therefore, a case study might be replicated in another setting and result in entirely different findings. Schramm writes that the case study "exists to systematize evidence as to suggest hypotheses for testing" (1971, p. 2). 
The case study presented in this paper could easily be reproduced at many large, corporate-owned newspapers across the United States.

A case study does not explore the entire organization but instead a particular issue or unit of analysis (Noor 2008, p. 1602). In this case study, the particular issue being studied is social media use and its effect on newsroom hierarchy, rules, and news distribution. Case studies also allow a researcher to capture change in an organization at a particular point in time (Noor 2008, p. 1603).

\section{Case Selection}

When The Metropolitan Post was selected as the subject of this case study, I entered the research under the assumption that the administration and staff would be working on a social media policy very soon. After observing newsroom interactions and interviewing members of the newspaper's staff, I found that policies for social media were not being pursued right now due to other priorities of the staff, including the deployment of more redesigned sections of the newspaper's website.

The newspaper was also selected due to the proximity of the newsroom to the researcher. Observing another newsroom in another part of the country for the same period of time would have proved cost-prohibitive. Several weeks were spent discussing access to the newsroom before research could begin. The Metropolitan Post is one of the 50 largest newspapers in the United States in terms of daily and Sunday print circulation. It is typical of most metropolitan newspapers in the United States in that it is owned by a corporate parent.

The corporate ownership of the newspaper was also a factor in selecting The Metropolitan Post. A case study of this organization would allow for an understanding of 
the influences on newsroom decisions and would help determine if newsroom policies are dictated at the local level or by someone in the parent company. Finally, since many newspapers are involved in a similar corporate model, the case study can be repeated at many newsrooms. The case study is not meant to imply that what is happening at The Metropolitan Post is happening at newspapers across the country, however.

\section{Data Collection}

Schramm proposes that there are four types of data important in conducting a case study, including observation, documents, interviews, and secondary analysis (1971, p. 12). In this case study, I have observed day-to-day operations in the newsroom, interviewed reporters and editors, and collected social media updates from the newspaper and staff members.

The collection of multiple sources of qualitative data ---- in particular for this case, interviews, observation and tweets ---- helps improve the validity and reliability of the research's findings (Noor 2008).

Newsroom observation. In order to gain an understanding of this particular newsroom's organization and culture, I observed in the newsroom of The Metropolitan Post for fourteen days over four weeks.

Stake suggests that much of the data gained in a case study comes as a researcher "becomes acquainted with the case" and is learned "informally" (2011, 49). I was allowed to sit at a desk in the newsroom, vacated by an editor who had recently retired. This perspective gave me a great vantage point of the web desk and the offices of the main editors in the newsroom. I still moved from floor-to-floor throughout the day to observe the activities of the other desks. In order to maintain the anonymity of the 
newsroom, I did not collect photographic evidence, but instead drew a diagram of the newspaper's office space to provide an example of how the news operations are separated during the construction process.

Berger writes that observation provides "a sense of context, which often helps explain what people do" $(2010,138)$. Observation was extremely helpful in understanding the ways social media was used in the news distribution process. Observation was also beneficial for developing an understanding of newsroom routines, including meetings and story creation.

During the observation period, I took notes about every development throughout the day. In situations where events were moving quickly and were developing throughout the day, I hyperlogged information using timestamps to keep an extremely accurate record. When I attended news meetings, I took notes on which stories were discussed and compared the items to what was shared on the newspaper's social media pages online.

Interviews. Nineteen reporters and editors were interviewed during the course of the case study. An attempt was made to select interview subjects that would represent the many facets of the newsroom. Therefore, I thought of individuals as belonging in several groups: Reporters and editors; staff members from various beats including features, sports, business, metro and the editorial writing department; and people with varying levels of social media experience.

The interviews were semi-structured in nature. Berger explains that this type of interview allows for a casual interview experience while ensuring that previously written questions are answered. Also interviewing allows the researcher to delve into places where observation cannot go and "understand why [people] do things, what motivates 
them, and what anxieties they have" $(2000,113)$. Staff members remained anonymous during interviews. As a result, each interview subject was allowed a chance to be completely honest and open about their thoughts of newsroom management without fear of reprimand by administrators. Interview subjects are identified by a first-name pseudonym.

Reporters and editors were asked about their work history with the newspaper and their own personal understanding of social media use. I also asked each person about their conversations with others in the newsroom about social media use as well as their impressions of attitudes toward social media use in the newsroom. Additionally, interview subjects were asked what they thought could be done to improve social media use at the newspaper. Due to the semi-structured nature of the interviews, staff members also talked about other aspects of the newsroom's culture, including the sense of competition reporters felt with local television stations and their frustration with not being encouraged to try new innovations with social media.

Interviews were audio recorded so that accurate transcripts of the conversations could be maintained.

Analysis of social media interaction. During the first two weeks of February, I collected screen captures of all Facebook posts and tweets from the newspaper as well as tweets from individuals who are a part of the newspaper's staff list of Twitter accounts online. The newspaper's tweets were analyzed to see how many contained only a headline and link, indicating that the newspaper's content management system automatically sent the tweet, compared to how many tweets were used to engage with readers. These numbers have become more important to the newspaper in the past few 
months now that they have used a service called Visual Revenue to help the web staff determine which stories are gaining the most clicks based off of Twitter traffic.

\section{Research Questions}

The following research questions are meant to provide a means of understanding how social media is used in the newsroom of a particular newspaper, The Metropolitan Post. Also explored is how social media is regarded by various stakeholders in the newsroom.

RQ1. How does social media change the way that reporters and editors distribute news to consumers?

RQ2. How has newsroom culture changed to adapt to social media use as a journalistic tool?

RQ3. Which group of stakeholders has the most influence in directing a company's social media policy? 


\section{Case Study}

This section will explore the role that social media plays in one newsroom, The Metropolitan Post, in the American Midwest.

In the past three years, The Metropolitan Post has attempted to embrace new technologies to meet the requirements of the digital age. In 2010, the newspaper created a social media editor position and charted various social media strategies, redesigned their website and instituted a subscription service for online content. The Metropolitan Post is a daily newspaper that sells more than one million copies of its print product each week. In the past six months, there has been a renewed focus on digital innovation. This focus has included the hiring of a new digital editor and a complete redesign of the newspaper's website.

This section will examine the newsroom's culture, focusing on the role of social media in a day-to-day setting.

\section{Definition of Terms}

The approach to social media consists of two parts. The first is a policy, a code of ethics, which informs reporters and editors how to use social media properly. Essentially, this is a list of "dos and don'ts" for Twitter, Facebook and other social media tools. The second part is a strategy that details the intended use of social media in the newsroom. A strategy should define the newspaper's goals - to increase readership, to foster engagement or to promote content -to indicate how those plans should be carried out. Throughout this research, the two parts are respectively referred to as a "social media policy" and "social media strategy." 


\section{Newsroom Routines}

In The Metropolitan Post's newsroom, the daily routine of the editors includes three important meetings. In the morning, a group of editors meet for an online rundown and for a morning news meeting. In the afternoon, the core group of editors met for an afternoon news budget meeting and to discuss story placement for the front page.

The morning web meeting. Every morning at nine, the newspaper's digital editor led a small meeting to discuss what each desk was working on for the day. Most of these stories were slated for print the following day, but each one would make it to the website as soon as possible throughout the day. Typically, editor representatives from sports, business, metro, features and the editorial staffs attended this meeting. One metro reporter who worked with the web team throughout the day, the social media editor and two web producers also attended.

The morning news meeting. As is typical with most major newspapers, the morning news meeting was a time to discuss the morning's newspaper and to find out what the different desks were working on for the next day's edition. The morning budget meeting was typically led by the newspaper's metro editor. Every department was represented by at least an assistant-level editor.

At this time, a working budget for the day was created so everyone would be aware of what each department was working on. Members from the photo staff were also on hand to discuss assignments for the day. The metro editor typically asks the social media editor what people are talking about online. The conversations about social media typically consisted of what stories from the day's print edition were getting the most play online. 
The afternoon news meeting. This meeting takes place every afternoon at four and is led by the managing editor of the newspaper. The focus of this meeting has shifted from what was planned for tomorrow's edition to what has been completed for tomorrow's edition. The section fronts and the front page stories are assigned for each department and a photo centerpiece is selected to run if necessary. The social media editor gives one more brief update about how stories are playing on social media while the assistant managing editor for digital gives website traffic information. She typically provided this information on high traffic days, including the day after the business explosion. However, she does not attend every meeting.

\section{History of Social Media at the Post}

As of March 2013, there is no official policy in place for how reporters and editors should use social media on a daily basis at The Metropolitan Post. Similarly, there is no official strategy for how the newspaper should be using social media to promote the work of the reporters and how staff members should interact with members of the public.

Currently, reporters and editors at The Metropolitan Post are not required to have a social media account of any kind. With the exception of the sports desk, there is no sort of social media policy or strategy in place. The social media editor maintains a list of the newspaper's staff on Twitter. At present, the list contains the Twitter accounts of 54 staff members. The list does not reflect the current staff, however, since at least two accounts listed belong to people who no longer work at the Post. The newsroom directory on the newspaper's website lists 140 staff members. Therefore, the list on Twitter accounts for less than 40 percent of the entire staff. 
On Twitter, the newspaper has approximately 35,500 followers. On Facebook, the newspaper has about 14,500 "likes" and on Google Plus, over 2,500 people include the newspaper in their circle of friends. This indicates that The Post has a direct social media reach of 52,500 viewers on the three social media networks. The St. Louis Post-Dispatch, which is similar in daily newspaper circulation to The Post has nearly 86,000 followers on the three social media networks.

The newspaper first hired a social media editor in January 2011. The editor who first held the job, "Janet," described the social media strategy of the newspaper then as "a free-for-all" where people had their own Facebook pages and the newspaper did not even have a Twitter account. In one conversation, Janet said she was hired because editors were looking for someone young to handle social media at the newspaper. At the time she was hired, only the newspaper's weekly entertainment magazine had a strategy for social media. The social media presence for the magazine consisted of an institutional Facebook and Twitter account.

Of the presence of social media at the newspaper, she said:

Most of us probably believe that social media is with us to stay and frankly I believe we should be more engaged in talking about new opportunities out there although we're more limited as a newspaper company in this area, finding our ways into other areas before we're way behind the curve again. I think newspapers are generally slow to respond to those things. (Author interview, February 15 2013).

The former social media editor, "Janet" said "My job was to come up with what the paper was going to do, create what the platforms were going to be and get everybody 
to do it." At that time, she said the strategy was based on the idea that Facebook was more popular than Twitter. As a result, a Facebook page was created for each department at the newspaper. But, within two months, the publisher ordered all of the pages to be closed in favor of one unified Facebook page for the whole newspaper. Currently, only the newspaper's editorial department and entertainment magazine have a departmental presence on Facebook or Twitter.

The deputy sports editor said that he felt the new approach worked because it led to individuals becoming the focus of followers on Facebook and Twitter but noted that he did not believe people wanted to listen to a "monolithic newspaper voice."

At the same time, Janet said that work on a document to distribute to reporters and editors began. While in the process of developing their plan, she said the newspaper's parent company said it would develop a social media ethics policy for the entire company instead.

"We've been waiting a long time for our corporate company to unveil an ethics policy," Janet said. "We do not have a social media policy or an ethics statement, because corporate said they would just do it for the whole company. We still do not have it and it has been two years."

When asked if the newspaper was required to wait on a directive from corporate, Janet said, "Sometimes, we do not. But since they said they would do it, we're still waiting." As an alternative, she said the newspaper has added a few items to the newspaper's overall ethics policy that are not specific to social media. She said the lack of specificity causes problems. When people end up breaking the rules, they simply say "I didn't know I couldn't do that." Janet left the role of social media editor in March 
2011. The current social media editor, "William," has held the job since then. The seventeen-year veteran of the newspaper that holds the job now is also juggling other jobs on a daily basis. He serves as the newspaper's reader representative and as the director of research.

To this day, nothing concerning social media has been put in writing, from corporate or from newsroom leaders. The editor-in-chief, "Richard," said:

We have a strategy. I do not think we've sat down and really wrote it out but you know, it has changed based on our personnel. It is a bit of a resource question as well. At one point, the strategy was to have social media handled by every department. But, that was too uneven as it turned out. The result of that was unevenness. (Author interview, March 1 2013)

The editor-in-chief said the decision to try to administer social media that way was based on the way the newspaper did everything else. He noted that it made sense because everyone was divided into departments already for web and print:

But, because the result was uneven, we came back to the idea that we needed an institutional approach and put one person in charge and need to have several other champions around it. That's sort of been our strategy. The social media editor is our primary social media person. A lot of things go through him. (Author interview, March 1 2013)

The assistant managing editor for digital, "Melissa," joined the newspaper staff six months ago. She's in charge of the website redesign and any digital enhancements to the website. She also works with the social media editor to determine the best practices for social media use in the newsroom. Melissa said: 
I coordinate our social media strategy with the social media editor. We do not have a formal strategy. It has been pretty organic since I've been here. But we talk pretty often about the kind of content we put on those channels. Our channels are primarily Facebook and Twitter. But, we do have Pinterest but I haven't had time to get into that. (Author interview, March 5 2013)

Melissa also said there currently is not a conversation among all staff members about the best way to use social media in the newsroom. "I do not have a lot of conversations with reporters [about social media] because they're not my direct reports. I'm dealing more with editors than reporters." She went on to say that in the days following a business explosion, she sent out an office-wide memo asking people to link to coverage from the newspaper's website rather than that of competitors.

In the past, an intern served as the newspaper's social media coordinator. According to Janet, this person was in charge of coordinating the newspaper's social media presence across platforms including Facebook and Twitter. But, even the intern had to split duties with a reporting job that she had on the business desk, according to Janet. When the intern left, the position was never filled. But, the current social media editor, William, said that he worked with the intern as he transitioned into his additional title of social media editor.

The attitudes toward social media use at the newspaper have been mixed at best. Many reporters and editors at The Metropolitan Post are quick to remind you that the staff there is a veteran one. Richard, the editor-in-chief has worked there for 16 years, the social media editor, William, for 17 and some reporters have been around for more than 
30 years. You can find the youngest staff members working on the newspaper's weekly entertainment magazine. The editor-in-chief said:

I think we've had mixed results, just to be candid. That's partly what you get when you get a mostly veteran staff. Although, I do not want to generalize because some of our most-tenured employees are some of our best social media assets. It is like almost any new initiative in the newsroom. There are early adopters and there are people that you've got to sort of drag to the well to drink. (Author interview, March 1 2013).

Even the social media editor says he thinks an overarching policy will not be useful to the newspaper. "It is pretty foolish to make any kind of blanket policy or recommendation," William said. He added:

One of the nuts and bolts that I sometimes remind people about is our code of ethics and conduct applies no matter what, no matter if it is about signs in your front yard or what you put on social media. (Author interview, February 19 2013).

\section{Typical Day for the Social Media Editor}

The social media editor's day starts in his office upstairs away from the newsroom. Early in the morning, one of his other roles as the newspaper's reader representative takes priority. He's already fielding phone calls, Facebook messages and e-mails about newspapers that weren't on doorsteps this morning. Social media has changed his job as a reader representative. He says that his roles as public editor and as social media editor have meshed well and that the web has changed the way he does his job. 
"There's a surprising amount of customer service you do via Twitter and Facebook," William said. He added:

I do not want to say it is annoying but I hate when I come in at 7:45 and I notice I've got a Facebook message that someone didn't get their paper. I take care of it that way. That's the sort of thing any ombudsman does a ton of anyway. You deal with a lot of misdirected customer service stuff. (Author interview, February 19 2013)

Around 9 a.m. each day, William makes his way down to the newsroom for a few meetings. The first meeting is a web meeting that provides editors a chance to discuss what their reporters are working on for the day. At the end of the meeting, the social media editor discusses what he thinks will play well on social media throughout the day. He then goes back upstairs to check on social media and other important tasks for the day before heading back down to the newsroom for the 10 a.m. budget meeting.

William says those meetings are important because he can look for what he calls "sticky stories":

I'm looking for opportunities to repackage existing stuff. I'm on the lookout for things we might want to promo in advance. For example, if we had a big section on personal finance for Sunday, I'd want to get the word out on Friday before and say 'Hey, go out on Sunday and buy a single copy.' Sometimes, it will be to point people to things that are coming up. But for the most part, anybody who says they are not looking for people to click on stories that sound really interesting is lying. There's nothing wrong with promoting your content as long as it is decent content. (Author interview, February 19 2013) 
On a slow news day, his social media editor position takes a more active role in his work. On one particularly slow day, February 13 , he is posting more manual updates than usual. As most people in the office that use Twitter do, the social media editor uses TweetDeck, a desktop client for Twitter, to keep up with what is going on with social media throughout the day. On his dashboard, he uses four columns. He is able to keep an eye on tweets from the main newspaper account, the tweets of people that the newspaper follows, tweets that include the Twitter handle of the newspaper (also known as replies) as well as direct messages that go to the newspaper's private inbox on Twitter.

Throughout the day, he will browse websites like Mashable and Buzzfeed to search for interesting links and stories. If he finds something incredibly interesting, he'll contact a reporter on the beat to see if it can be easily localized. If not, he has an editor check the wires to find something to use for the website. He tells me that this is the preferred way to share this type of information, noting that he never sends out a link to an external website from the institutional accounts unless there's absolutely no way to get a story on the website. He says the goal of social media is simple - to drive traffic to The Metropolitan Post's website.

But, sometimes, he says, there are some things like a slideshow of Sports Illustrated Swimsuit edition models that do not need links on social media. "That will be read on its own," William said. As he updates posts on the social media accounts, he adds the information with a timestamp to a Google document, which allows for others to see and edit the list. Other people that can see the list are the three daily web producers on duty, which post content online, as well as the assistant managing editor for digital. Every 
day, a new document is created so an accurate track of who did what throughout the day can be kept.

\section{How News Becomes A Tweet}

Social media updates on these three accounts are managed primarily by the social media editor with some help from the digital editor from time to time. A majority of the updates on the newspaper's Twitter account are automated and are not written by a person in the newsroom. Instead, the tweet is written when an editor places the story online with a headline written at that time.

William said that the stories are curated by editors who place stories into a feed on the website - specifically the breaking news feed. If an editor makes an error in the headline, it is going to show up in the Twitter feed even if the person goes back and makes the change later. There's no way to stop the tweet once the story has been posted to the website. The only way is to delete the tweet once it shows up on Twitter. Typically, the tweet shows up just a few minutes after the story has been posted.

But, during the first week of my visit, there was a problem with tweets being sent from the content management system. According to William, there was a 15 minute lag from the time the story was published on the website until the tweet goes out on the main account. A day or two before we discussed this, he told me that people online were noticing the problem, especially with sports stories. One story, which was a halftime update for a college basketball game, was tweeted well into the second half. To fix this problem, the newspaper's only web programmer had to repair the script that allowed the tweet to leave the website's content management system. 
Facebook updates are made mostly by the social media editor. There's no way to automate those types of updates at this time. The social media editor said he looks for stories that will be "talkers" on Facebook in order to increase conversation about the story. He said he feels Facebook is one place where people are more likely to have a conversation about the news rather than simply share it.

The social media editor said that he and the assistant managing editor for digital sometimes disagree on what to post on social media. In particular, the social media editor said he does not like posting political posts to the Facebook page that solicit readers' opinion with a question while the digital editor is fine with it. For example, during Barack Obama's State of the Union address, the digital editor created a post, with a link to the address and simply asked, "What did you think of the President's proposals? Read the address text here if you missed it." The social media editor said that he feels these posts make the environment on Facebook "more divisive."

\section{Using Social Media in Breaking News}

During the four weeks I spent in The Metropolitan Post's newsroom, I was able to observe how the staff used social media in two major breaking news situations. In February, an explosion killed one person and injured 15 at a business in the city. During the event, the newspaper used social media and other digital tools to tell the stories of the events.

Business explosion. Shortly before 8 p.m., I arrived to the Metropolitan Post's newsroom. I quickly realized it was an all-hands-on-deck type of situation. Evening web producers were joined by morning web producers who had returned to the newsroom as many reporters had scattered throughout the city near the scene of the explosion. Other 
reporters had come to the newsroom to help collect information from reporters in the field to write stories for the website.

The assistant managing editor for digital, Melissa, who worked in the newsroom that night explained that the newspaper's coverage of the event was a "bad experience." She said:

In the first 15 minutes, a reporter came up to me and said 'I'm the one who's going.' I was a little disappointed because I knew this person was not really good with social media but she was really eager to go. So, I told her 'You need to get out there and start tweeting.' (Author interview, March 5 2013).

The digital editor said she knew tweeting would be important from the scene since it would take some time to get an initial report back for the website. She wanted the news to be posted quickly, but talked about the competition the newspaper faces in the city.

Melissa said that while TV is faster, the newspaper's reporting is better:

TV always beats us. They just do. They have the capability of getting there quickly, they can do the video, they can get on the air quickly. But, we think we're better in the end because we can do a broader, fuller report. (Author interview, March 5 2013).

To facilitate an improved response, the digital editor said she tried to help the reporter learn Twitter in a few moments before the reporter headed out into the field. Melissa said that the reporter asked her for help in tweeting. She said it quickly became clear that she did not know how to use Twitter when the application was not loaded on the reporter's phone. When she got the app running, the reporter did not know 
the password. The reporter ultimately asked Melissa if she could use her personal cell phone. Melissa said she had to decline since she needed it to stay in touch with reporters. She said the experience revealed flaws in the way the newspaper uses social media to cover breaking news:

What that told me was that I need to sit with the metro editor and we need to have a crisis team approach so that if this happens in the morning we can send a reporter, a photographer right away on the scene and the same thing for afternoon and evenings. That way, we can have somebody out there tweeting right away or even text us information back so we know what's going on quickly. That was not a good example of what we're capable of doing. (Author interview, March 5 2013).

The editor-in-chief of the newspaper said he has more ambitious plans for how reporters can use social media in the next breaking news event. Richard said that he has encouraged the staff and spoke with some of the employees about telling a narrative story through Twitter.

He described his vision as:

One where every post upon post, when you take that collectively together, there's a story there. One hundred and forty characters at a time, you get a sense of a narrative story telling device. So, it is not just an explosion at a business, but it is reporting out every micro detail the same way a narrative writer would share those details(Author interview, March 1 2013). 
He described this detail as a reporter using "access flaunt" to allow readers to go on a journey with the reporter. He said that he feels the immediacy of Twitter would allow reporters to tell narrative stories just like a story for the newspaper.

The digital editor, Melissa, said that in order for story telling like this to happen, "you really need to have a smart, experienced tweeter as well as someone who has those writing skills. I don't think there are a lot of people who can do both of those things well."

The following is a timeline of events in the newsroom following the explosion. The purpose is to show how the staff reacted to a developing news situation and how social media played a role.

\section{Tuesday, February 19, 2013}

8:11 p.m. Digital editor sends a hospital update out on Twitter.

8:20 p.m. Digital editor posts an update on Facebook that reports the gas at the scene is turned off. At the same time, a metro editor sends out a rundown [the plan for news coverage] to the staff. In it there is nothing about social media, but the digital editor continues to send out updates.

8:43 p.m. A reporter comes to the digital editor's desk and says that she has two pieces of information for posting on Twitter.

8:45 p.m. A person comments on a Facebook status update about the gas being turned off. The person writes a post saying that a local TV station is reporting the gas is still leaking.

9:07 p.m. The information given to the digital editor by the reporter is sent out over Twitter. 
9:12 p.m. Digital editor is on the phone with a reporter at the scene and taking notes. The reporter tells her that the gas may not be off.

9:17 p.m. A reporter in the newsroom is calling phone numbers she got from Facebook messages. Earlier in the evening, she reported to others in the newsroom that she was gathering sources from social media.

9:27 p.m. An automatic tweet with a sports update goes out. At the same time, the digital editor is compiling tweets for a Storify widget. This tool allows for Twitter and Facebook posts to be saved in one place to create a story, even if the original posts are deleted. The editor-in-chief, head designer and two others are working on the front page at the same time.

9:42 p.m. At this time, it has been 34 minutes since the last tweet with the commonly used hashtag was sent out on Twitter.

9:50 p.m. The digital editor is making the case to get a photographer in the air with one of the local television stations.

9:57 p.m. The digital editor is still juggling the creation of a Storify widget. At the same time, one of the local television stations is now reporting that the gas leak has not been capped.

9:59 p.m. As administrators bring in a meal for the staff, the digital editor asks one of the other editors to send at least one tweet from what is being said on the televised press conference.

10:01 p.m. Two reporters are talking about social media updates. A busboy they originally thought was missing was not at work. Through the social media updates, they 
have the name of a woman who is possibly missing. The next day, it is confirmed that the woman died in the explosion.

10:05 p.m. The televisions in the newsroom have been turned down. No one is actively watching the press conference. The digital editor, editor-in-chief and another editor are now looking at the website's pageviews.

\section{Wednesday, February 20, 2013}

10:17 a.m. During the morning news meeting, the metro editor gets a text. A body has been pulled from the rubble.

10:33 a.m. An editorial writer with the newspaper sends out a tweet reporting that a body has been found, citing the mayor. In three minutes, there have already been eight retweets.

10:36 a.m. The social media editor sends out a modified retweet of the editorial writer's tweet about the hospital update. Other outlets are reporting about the fatality.

10:40 a.m. The editorial writer tweets another update from the mayor. There is still no tweet from the main newspaper account.

10:40 a.m. The newspaper's Twitter account sends out the link to a story about the volunteers who helped at the explosion and fire.

10:48 a.m. A story about the fatality is reported on the newspaper's website.

10:51 a.m. The social media editor calls the editorial writer and asks her to use the preferred hashtag for the disaster.

10:56 a.m. The social media editor tells me "We've got our story" on the death at the business. 
11:02 a.m. The social media editor posts an update to the newspaper's Facebook page.

4:36 p.m. The Fox affiliate in town is reporting the name of the person who died in the explosion.

4:49 p.m. News outlets, with the Post being the exception, are tweeting information from the live press conference. The mayor says there is no positive identification. The Fox affiliate updates the story to remove the information.

4:58 p.m. There are many updates still coming in from television and radio stations across town. There is still no update from the newspaper on any social media tool.

4:58 p.m. However, a Facebook update does go out at this time while the press conference is going on. It is an Associated Press story about Google Glass.

5:02 p.m. A few people are standing around televisions in the newsroom watching the press conference. No one from the web staff seems to be pushing anything to the web.

5:05 p.m. The newspaper's basketball reporter tweets that he's received a copy of allegations against a university's coach.

5:07 p.m. The mayor's press conference comes to an end. There were no live updates from anyone associated with the newspaper.

5:07 p.m. The basketball reporter is still sending out updates about the investigation report piece-by-piece via Twitter. 
5:09 p.m. A reader tweets about the city's mayor calling out the newspaper's "shitty reporting" on the fire. The reader uses the newspaper's Twitter username in the tweet.

5:14 p.m. A story about a missing dog after the fire is posted on the newspaper's website. It is the second such story of the day.

5:18 p.m. The newspaper's content management system sends out an automated tweet about the missing dog. This is just minutes after the press conference about a fatality in the fire.

5:30 p.m. I walked up to the social media editor's office to see if he was still there so I could ask about the tweets. The door was locked. He had already left for the day. The last time I can confirm he was there was a few minutes before 5 p.m. when the Facebook update on Google Glass was sent out. The digital editor is still working around the office.

The newspaper's editor-in-chief said that there were more than 25 reporters and photographers on the streets covering the story that evening. Richard said that one of the first things asked in the newsroom was "Okay, who's sending out social media updates?" He said that some reporters were able to send their own updates, while others like the reporter mentioned by the digital editor, did not understand how to send updates via social media.

One metro reporter, Karen, said that on the night of the explosion, she was heading home when she saw the smoke and got a call from another reporter. The two reporters shared numbers to try in the newsroom to figure out where they should each be. Should they be on the scene or in the newsroom relaying information from reporters 
already there? Karen said she got a text from the reporter that read "I hate this fucking place because I can't get through to anybody and something is on fire and I can't get through." She said they left messages with multiple reporters and editors and was frustrated that she could not get someone on the phone. Ultimately, both reporters went to the newsroom.

The next morning, the social media editor, William, told Melissa that she should have called him, noting that he had "checked out" from the news coverage and from Twitter for the day.

\section{Analysis of Institutional Tweets}

Over a 13-day period that overlapped with my newsroom observations, I collected tweets from the newspaper's official Twitter feed. In the analysis, I have recorded some simple metrics that provide a snapshot of how the newspaper uses Twitter. During this period, there were a few major news stories that occurred, including Pope Benedict XVI's announcement on February 11, 2013 that he would resign the Papacy and President Obama's State of the Union Address on February 12, 2013.

The newspaper's sharing of information on Twitter drops dramatically on the weekend. The number of tweets sent out on Saturdays and Sundays is less than half of a typical weekday. When the newspaper does share information on Twitter, it does so with only a headline and a link. Of the 525 tweets that were analyzed, 404 (76.95 percent) of them consisted of only a headline and a link. Only 11.24 percent of tweets sent out during this time period contained a hashtag, user mention, a question or any sort of customization beyond a simple headline and link. 
On some occasions, the newspaper's main account would feature tweets that originated with the newspaper's editors or reporters or from some external source. Those retweets account for 12.19 percent of the newspaper's overall tweets during the 13-day period. Some of the tweets were retweeted because they mentioned the newspaper while others were from reporters or writers who covered a specific beat.

Finally, over the 13-day period only six tweets were sent in reply to other Twitter users. In all of the cases, these tweets were sent to either thank a person for feedback on the paper or the website or to try to help a customer with a problem.

The two busiest days for the newspaper were on February 11 and February 12, 2013, which corresponded with the pope's resignation announcement and the president's State of the Union address. On the day of the State of the Union Address, the percentage of custom tweets was 25.86 percent, which is fourteen points higher than the average for the 13-day period.

\section{Artifacts}

The changes in the newsroom are apparent as you walk through the main entrance. A large plastic sheet hangs in the middle of the room, separating the newly renovated half of the office from the construction site on the other side. As a result, the operations of the newspaper are scattered throughout the over 100-year-old building. Primarily features editors and reporters occupy the new half of the newsroom.

In this temporary miniature newsroom, the features department and the newspaper's design team take up much of the space. Along the wall are offices of the editor-in-chief, the managing editor and other head editors. A programmer as well as 
photo editors are scattered throughout the room. In an area known to staff as "The Octagon" near the newsroom's entrance, sits the web team.

The sports staff is located in an office up a short staircase in a hall across from the newsroom. I'm quickly told that the sports staff is rarely there, however. On the day before traveling to the site of the city's Major League Baseball team's spring training camp, one sports staff member works in "The Octagon." She splits her time evenly between the production of the print and digital products.

Up another staircase, on a floor above the newsroom are the business and metro news desks. The metro desk has two representatives downstairs in "The Octagon" - an editor and a reporter. One of the most visible artifacts that could explain the disconnect between the roles of social media and traditional media is the separation of the social media editor from the rest of the newsroom. His desk is in the back of the newspaper's library, which is on another floor. His only regular contact with the newsroom is the three daily meetings he attends. Before he became the social media editor, William had a staff of 13 people in his role as the newspaper's director of research. Now, he is the only one. Today, social media editor is not William's only title. He's also the newspaper's reader representative and the organization's director of research.

Just like the offices around the newsroom, the social media strategies of this daily newspaper are in a state of flux.

It is unclear if a written document detailing the newspaper's social media strategy and policy have actually existed. A features editor, who previously served as the newspaper's social media editor, said that a document was being worked on two years ago and supplied to employees. However, she never could produce a copy for me. The 
current social media editor said that he was working with a corporate team to figure out the best strategy for social media, which is still in the works. Both the editor-in-chief and the assistant managing editor for digital both said that strategies have been discussed, but that they've never been written down. As discussed earlier in the section "A History of Social Media at the Post," the social media editor made a statement saying that he saw no point in having a blanket policy or strategy for social media use.

A lack of resources for reporters is also an issue for the staff at The Metropolitan Post. The editor-in-chief, Richard, said:

I'm not complaining but we're not always as resourced as we should be. I have a smartphone and I have a tablet. I bought these on my own. They're not companyprovided and we live in lean times. Not every single reporter has a smartphone, so trust me when I say that it becomes a very important piece of the puzzle. (Author interview, March 1 2013).

When reporters want to have tools such as a smartphone to use with Twitter, they have to purchase that on their own. Even when wanting to learn more about social media, it is up to individuals to make an effort to learn more about the tools. Reporters said there is no push from editors to use social media on a day-to-day basis.

Jake is a reporter on the metro desk. But for three hours a day, he is a multimedia reporter that works for Melissa, the digital editor. In September 2012, he covered a hearing using Twitter as a live blogging tool. His editors originated the request to live tweet the event. Jake said that out of all the reporters on the metro desk, he felt he had the most knowledge about social media. As he covered the hearing, Jake used his own firstgeneration iPad to tweet from a media room outside the courtroom. 
On the metro desk, there is no sort of allowance for reporters to purchase the digital tools they need. "This is the original iPad with 3G," Jake said. "I personally don't have a data plan. If I absolutely need to have 3G, I will go ahead and purchase it and cancel at the end of the month." Jake is also interested in video reporting, but when the photo staff purchased new equipment, he said it was geared toward what that particular staff needed. But, the metro staff's priority is not video, he said.

The editor-in-chief added that these resources become a factor in the conversation of what the newspaper's digital future is going to look like. For one reporter on the metro desk, one way the sports editor got more of his staff on Twitter was to make sure that every reporter had a smartphone in his or her hands. Some reporters already had a smartphone, but not all. However, on the sports desk, technological resources are key. James, the sports editor, said that he worked with those reporters to get a phone.

He described the program as a "complete buy-in" by his staff. James said that the department has overcome budgetary limitations to make the phones a reality. In fact, reporters in the sports department are required to have a cell phone just like they're required to have a laptop.

Besides the technological resources, the editor-in-chief of the newspaper said that the sports department has been a focus of social media efforts for a while now, but there must be a wait-and-see approach for what to do with the technology next.

Certainly a few years ago, I think it was seen primarily as a driver in sports," the editor-in-chief said. "It was a way to build a brand in sports. We've built some strong Twitter accounts around a couple of sports guys who were in the 10,000 and above followers range. So, it is still evolving. We're still going through the 
evolution of that. A lot of what happens in our business are papers watching other papers. There's a lot of copy cat stuff that occurs in the newspaper industry. Everyone is watching carefully to see how it will continue to evolve. (Author interview, March 1 2013).

During my observation period, however, I saw that not all departments are as equipped as the sports department. On one occasion, the digital editor had been expecting a story from the business desk about a rally of realtors at the state capitol. She told one of the business editors that the reporters need to be thinking of web deadlines, not just print deadlines. As the two spoke in the newsroom, it became clear that the reporter didn't have a smartphone to send updates with.

Furthermore, the reporter had not even carried a laptop to the event with him, meaning he had to file the story when he returned to the newsroom. The drive from the state capital to the newsroom is approximately an hour. Before the reporter had returned to the newsroom, local television stations had already filed stories for their midday newscasts.

The editor-in-chief said he's trying to address equipment shortages: I'm trying to fix that and address that. We have gotten some equipment through a corporate program. I've tried to add phones here and there just on my own within my budget. I've tried to do some things. Ideally, every reporter would have a tablet. Every reporter would have a smartphone and our photographers would have one as well. (Author interview, March 1 2013). 
Jake said that the focus on adding mobile equipment is not a priority for his bosses on the metro desk. "What I've found is that basically if you wait for someone to buy you the equipment that you need, you will be waiting forever."

\section{Values}

The values of a newsroom consist of the beliefs of the members of a newsroom. Reporters and editors talked about their beliefs of how social media should be used in the delivery of news. The values drive an organization to do the work that it does, but as I discuss later, the assumptions of staff members in the newsroom are what results in action (or inaction) by the members of the newspaper's leadership team.

Delivery of News vs. Branding of Reporters. The staff's perception on using social media as a journalistic tool varies from editor to reporter. Everyone interviewed agreed that it is valuable to the newspaper in one way or another. Where employees differ is their opinion on how to best use social media. A few see it as a way to deliver news as quickly as possible and to build sources while others see it simply as a way to promote a reporters content and to build a brand.

The newspaper's business editor, Ronald, is one of those people in the latter category. He said social media has made it easier to communicate with readers and to tell people what content his department is producing.

He said that he feels Twitter has two purposes: Sharing the newspaper's content or pointing people to other information available to them while building a person's brand. Although, the business editor says he only uses it to share links instead of trying to brand himself. "I'm not sure an editor at a newspaper needs a brand," Ronald said. "He or she 
has to help shepherd other peoples' brand." Ronald also said it is his job to focus on the newspaper's brand before focusing on that of any individual.

The editor-in-chief chose to focus on the newspaper's successful avoidance of inappropriate content being posted to social media sites as having a positive impact on branding. He said he's never had an issue with a reporter or editor tweeting content that was questionable online that would cause a problem for the newspaper:

Your brand name people can affect the newspaper through a tweet or Facebook post that they put up. You still have the human factor. Any time you have the human factor, great accessibility and no editor in between you and that content, there's always danger inherent in a scenario like that. Fortunately for us, we haven't had a high profile episode or a major snafu that we've had to deal with. (Author interview, March 1 2013).

On one occasion, an employee showed me tweets that she had taken screen shots of. The tweets were from an editor in the newsroom and make references to male and female genitalia, but the words were not being used in an appropriate manner. However, she said there was nothing she could do about it because there is no social media policy in place. She said the newspaper's editor-in-chief would have to handle it.

The business editor said social media has made it easier to communicate with readers and to tell people what content they can provide. Ronald said he believed Facebook and Twitter were more about popular culture than the subject matter his desk covers, making it less useful to him in that regard. He said he also encourages his reporters to share the content. "It gives me, as an editor, another window on what people are thinking out there," Ronald said. "That's the main benefit to me." 
On the matter of sharing the newspaper's content, the editor-in-chief said that on most days it is:

Making sure that our best content is published in that realm as well. For me, as an editor, I want to make sure that the great material that we're doing gets recognized, gets tweeted out. Again, that's just on an average day. When you've got just your regular run of breaking news, I think what you're looking for is that approach. (Author interview, March 1 2013).

The business editor's other concern is information on Twitter is that it is public and that his reporters are supposed to be finding information that is not public or that people are not thinking about already. "Twitter can point us in the right direction, but so do letters to the editor, so does a phone call, so does e-mail. So I do not see it as that different from a lot of other ways."

The deputy sports editor, Matt, however, sees the public information found on Twitter to be an asset to his reporters, especially on game day. Matt said, "You've potentially got 16,300 reporters there who are seeing things. We've only got one person on press row. There's only so much they can see."

One of the business reporters and columnists, Sarah, said she uses Twitter as one of her main tools for watching sources. She uses Twitter as a source-development tool. When new businesses follow Sarah on Twitter, she follows them back to keep up with announcements and updates from each of them. Instead of reaching out to people, she uses it to keep a watchful eye on the business community in town. She said she is wary however of using it to reach out to sources. 
Sarah said she uses a Facebook fan page more than Twitter to interact with readers. She said the main use of the page is to post links to stories in order to drive traffic to the newspaper's website and to answer readers' questions about local business happenings. Although she only has around 1,200 followers, Sarah said "If that's what the people want, then I'm going to do it." Even though she is a columnist, the reporter said she is careful about injecting opinion into her posts on social media. She also said that she is not comfortable with asking people for help with stories via social media.

"I know that's a tool and is probably something I'll use more in the future but I'm still a little uncomfortable with trying to get sources that way. I do not know how much I trust that." Sarah was the first business reporter to use social media on the staff and said it took her several months just to get her social media information published in the newspaper. Her editor commented that she was just going to use it for "letting people know what you had for breakfast." She had to counter by touting the advantages of using social media including driving traffic to the newspaper's website.

Although she touted the benefits of social media when first initiating a presence online, Sarah said she was not pushy about urging others to use the online tools, but instead to help anyone who needed it. The feedback she heard from most people was that they didn't have time to use social media in their day-to-day work. "People move pretty slow on this desk," Sarah said of social media adoption by business reporters. Conversely, she said there's been no urging by editors in the department for reporters to use social media day-to-day.

The business editor made his reason clear for why there is not a large push on having people use social media all the time. Ronald said he understands that social media 
helps a journalist check "the pulse of the people" but that it does not excuse reporters from maintaining the traditional values of journalism:

If people are tweeting all day, they are not talking to sources, they are not digging up documents and spending time with documents. They are not looking at spreadsheets and putting two and two together, which is what our real function is (Author interview, March 1 2013).

Using Social Media as a News Tool. The digital editor said that the use of social media, including Twitter, by reporters mostly depends on the type of story they're covering. In the cases of planned events, the reporter that works with the digital team typically creates a plan of action for those events. Other times, she said the staff will use tools like Storify and CoverItLive to aggregate tweets and short reports. Sometimes, the Twitter feed becomes the main news source for readers until a story can be posted online.

One reporter, Karen, who has worked at the newspaper for eight years, does not use social media because she does not feel that she is encouraged to do so, but she said that she understands the importance of using the tools, especially in a breaking news situation.

Karen said that using social media during breaking news is essential: I go to breaking news events and that is my passion and now I realize that if you're not using social media, you're not really covering breaking news. So many people that I know get their first initial news on social media. They wait for the newspaper still but they want it now and they go to Twitter and Facebook. (Author interview, March 1 2013). 
Karen first joined Twitter four years ago when she worked on a story about the social media service but has used it only a handful of times since joining:

I did that story, got a Twitter account and was basically told by an editor not to do it because I'm a general assignments reporter. The editor said that I worked on the bigger stories and that we wouldn't want to let the other media know what we're working on. (Author interview, March 1 2013).

When she has used it, Karen said she used Facebook and Twitter to reach out to people affected by a storm. She described the effort as a "news generator" rather than a "news sharing" tool.

But, she said that she has seen a slight shift of attitude toward social media since 2012, when editors realized their submission for a Pulitzer Prize in breaking news coverage did not contain enough social media.

"An editor told me 'Shit, we do not have a lot of social media.' A year before we knew no one won the Pulitzer for breaking news because there was not enough social media or multimedia," she said. The reporter added that at the time of coverage, 12 tweets over a two-day period seemed like plenty. In hindsight, she said the social media presence was "laughable."

The editor-in-chief said:

Right now, we're in a situation where we can certainly use more people on the social media front, more people thinking about it, more people whose first thought in a breaking news situation is to use social media. We could definitely use more help on that front (Author interview, March 1 2013). 
He added that any reporters out on the front lines of breaking news need to be comfortable with the social media tools.

Jake said that he uses Twitter as if it's a police scanner. "This is more of a tool where I can hear what people are talking about as opposed to what authorities are talking about," he said. With his general assignment duties, Jake said it's hard to keep up with everything on Twitter.

Richard said that demands change over time and that more questions come up such as "Should we be sending that tweet or should we be shooting video?" He said that reporters and photographers need to be doing both. He added:

Are you actually remembering to do what you were absolutely sent down there to do, which is report? A very smart writer once said to me, 'There is no writing without reporting.' I would say the same thing about social media. It has to be reporting based. (Author interview, March 1 2013).

However, on the sports desk, the core reporting skills are still there in conjunction with the social media skills reporters have learned. According to the deputy sports editor, the same rules that apply for the print product apply to the way the department's reporters are instructed to use Twitter. "We still hold all of our verification practices," Matt said. "Twitter hasn't eliminated any of those guidelines."

But on the night of the business explosion, Karen said that no one from the metro desk was tweeting from the scene. As a result, she was relaying information to the digital editor, Melissa, so it could be posted on social media.

[Melissa] should not have to go through the newsroom with her computer collecting information for Twitter," Karen said. "We should have people on the 
scene who know the first thing to do is tweet. I would like to know of the 11 reporters that were out there, who was tweeting? Because I don't think one was and that is a huge problem. (Author interview, March 12013 ).

Using Social Media to Engage with Readers. The editor-in-chief said that the editorial value of social media has been solidly established. "I understand it in the sense that it is another tool in our toolbelt to get our content in front of new readers," Richard said. One video editor with the newspaper said that the organization broadcasts too much. The video editor, Daniel said: I think you've got to get out there and have more fun with it. You've got to take yourself much less serious. I know we have to be careful with our branding, but go out there and have fun, be social, engage with people and be a part of the community. Show people that you're out there and not just broadcast from the newsroom. I think that's huge. (Author interview, March 6 2013).

The social media editor said that engagement with readers is important, but believes that there are two ways to do it. He said that a journalist needs to determine early on if they want to use social media to simply promote the stories they write or if they want to have a conversation. Additionally, he said that social media provides a way for readers to react to content quickly.

He said, that before social media, "There was not a middle-of-the-night, immediate response. I think that has amped up the negative much more than the positive. It really has amped up the intensity in what I call the outrage factor. There's no question about it." This increased engagement can definitely be seen at times when people do not like what they see in the newspaper. 
On February 9, the newspaper's editorial cartoonist drew a cartoon that many people found to be offensive to people supporting the U.S. military's actions overseas. A few days later, a conservative website run by Glenn Beck, posted a link to the story, characterizing it as an attack on a sniper that was shot and killed.

People began to flood the newspaper's Facebook page with comments about the cartoon on stories that were not related to it. The social media editor spent time deleting those comments and drafting a response, which he posted to Facebook. With the response, he hoped to provide readers with context and to solicit their responses. In the post, he wrote:

Most messages have been nasty, directly threatening, or both. It is an insult to the many sane, civil people who disagree with the content of the cartoon for anyone to use profanity or intimidation in expressing their point of view. (Facebook post, February 15 2013).

In the end, the post had more than 1,200 comments and was shared more than 300 times. A majority of comments were violent in nature, with the cartoonist and the editorial page director receiving death threats for running such a cartoon. In a conversation between the social media editor and the publisher of the newspaper, the two discussed that the cartoonist was told to leave his home for the weekend and that the city's police department had been notified.

One comment on the Facebook post read, "I would weep for a dead reporter or an editorial cartoonist. Not because its sad but uproariously funny. Kinda like when a clown dies." Another comment stated "Absolutely disgusting! Someone should torch your offices while everyone stands outside laugh like a big joke with all you burning alive 
inside." Few people came to the defense of the cartoonist and the newspaper. In part, one person wrote "You may not like this cartoon, but you do not get to choose which amendment to support. You either take them all, or none," in regards to people saying that the cartoonist's first amendment rights did not allow him to draw such a cartoon.

In the case of the cartoon, the social media editor reached out for engagement. For one columnist at the newspaper, she has struggled with engagement for nearly 10 years now.

The entertainment columnist's first ventures into social media included using MySpace to share nightlife columns. Her reason for creating the page was to stop readers from going to her personal page, which she did not use for work at all. She said when Facebook came along, the same thing happened. She used both of the pages to redirect readers to an account associated with her work.

"I didn't know how to go about rejecting them," Alexandria said. "As a columnist, you want to be engaging and have connectivity. But, you also do not want to give them every little bit of your life." To give readers that access, she began creating lists on Facebook to control access to her information. She said she quickly found that to be a tedious task and opted to create a fan page. At one point, information that she was engaged leaked to local bloggers.

"They [editors] always wanted me to do social media because that seems to make sense for a columnist," Alexandria said. "The Internet was the one place I had a sense of anonymity as a lifestyle columnist." She said the idea of having to be "owned" by her readers on social media was frustrating. She also had a private Twitter account that she made public less than a year ago. 
"It just seemed like the right thing to do," Alexandria said of the move. "If people read you long enough, they will find you. People were even finding me with my pseudonym on Twitter." Since moving to a professional account, the columnist said she has found herself tweeting more than she used to, noting that she does not get the negative feedback from readers that she expected. "It almost changed my relationship with social forums," she said.

Alexandria said that conversations on Twitter have led to columns that appear in print. She said that social media also allows her to have a better connection to readers. In her interview, she said "We watch the Oscars together," referring to her readers as part of her own group when live blogging the Oscars awards ceremony on Twitter. "Twitter has been the one safe place I can interact with my readers without the trolling," Alexandria said.

The entertainment columnist described social media as a "flood of convenience," noting that it is easy to become lazy in the process.

"Nobody wants links thrown at them all day," Alexandria said. "You want the links but you also need connectivity and it is hard to connect to a flood of links."

For one reporter-turned-editor on the metro desk, Thomas, he found the need to use social media dwindle as he started to drop his reporting duties from his daily schedule. He sees social media as a tool for sharing with a specific audience, not a broad one. "Even when I'm reporting now, I'm not reporting one subject area. If I were to tweet out about all of the stories I was doing, it wouldn't be helpful to my audience. They're not interested in me, per se." He said the primary value of social media to him was to 
follow other people and that there was very little focus on branding himself since he said he never had a very high profile online.

He said when Twitter first came along, he saw it as just another tool piled onto his already technology-filled day including two e-mail accounts "and a million other ways" to get in touch with him. He added that he did not see the utility of it. The editor said he still has trouble getting acquainted with tools like Reddit and Pinterest. With his e-mail, Twitter account, chat capabilities, Facebook and other tools, he said he wishes he could get rid of most of these tools that he uses on a daily basis.

The business reporter said she was frustrated by the lack of promotion of social media by people in the newsroom. One specific instance was the removal of taglines from the end of print stories. These taglines included her Twitter username as well as a link to her Facebook page. She believes that the taglines added the value of creating a dialogue between readers and reporters.

"I do not see it as something that is a priority on our desk at all," Sarah said. "When they're taking out the [social media] address, it seems to me that they do not feel that it is important." She said that readers need to know that the reporters are there for them.

Jake, a reporter on the metro desk, expressed similar frustration with the removal of social media taglines from his stories in print and online. He said:

"I go back and try to sneak it in. They allow sports to do it. It's kind of a gray area. There's times where I've tried to get it in before and it has been cut out. Sometimes you have to give up and then editors change the policy and don't necessarily tell everyone" (Author interview, March 1, 2013). 
He added that there was once an office-wide copy desk that handled all stories for print and online but noted that copy editors had taken a hit in previous layoffs, leaving each department to have their own copy editors. The sports department is the only desk to consistently have these taglines. The deputy sports editor said he has to fight for those on a regular basis.

"There are some people in the newsroom that feel like Sports is a renegade on this, having different taglines from the rest of the newsroom but it is definitely important," Matt said. He called the cutting of taglines from stories a lazy trend.

Throughout my observations and in interviews with staff members, the one place that everyone pointed to as an example of where social media is taken seriously was the sports department. The department is the successful example mentioned most by everyone interviewed. What makes the sports department different from others at the newspaper? The newspaper's current sports editor, who joined the staff in December 2010, said that it has been all about getting his staff to subscribe to the notion that social media can improve the way they tell stories.

The sports editor said:

We do not operate on a working-toward-the-evening publication for the next day cycle anymore. I do not consume my news once a day anymore. I get my news via Twitter as much as I do via our site or other news sites. I want people to subscribe to our newspaper but I realize the distribution and consumption models have changed and will continue to change. (Author interview, February 28 2013). At first, Twitter was a foreign concept to many of the veteran sports reporters. As for himself, the sports editor said the newspaper's football columnist helped him 
understand the importance of being agile on Twitter. "I know that these days we are breaking stories on Twitter," the sports editor said. "Everyone's breaking stories on Twitter."

The sports editor said the way to get reporters on board with Twitter took some time but explained the steps that the staff took. He said the first step was to help the reporters not be afraid of Twitter. The next step was to get the reporters to realize that they could still be first on stories with Twitter by tweeting out the news they found before posting it to the website and then tweeting a link to the story. The sports editor described that as the department's "protocol" for sharing information on social media. Simply put, a reporter breaks the news on Twitter, then writes a story for the website. The reporter then goes back to Twitter to promote the finished story.

Even once the reporters started to use social media in this way, the sports editor said there was a rocky start. But, over time, their view on social media in the newsroom changed and became a new normal:

They didn't like it as social media became more of a part of our day-to-day operation and our reality. They didn't like that they weren't breaking stories for print anymore. Well, here's your answer reporter...break it with a tweet. All of us had a hard time wrapping our mind around that for a while. Now it is such second nature that I can't even imagine doing it any other way. (Author interview, February 28 2013).

A sports reporter that covers college basketball describes himself as a late adopter of Twitter, joining the social networking site in early 2011 when he was covering the 
city's Major League Baseball team. Before, he was covering high school sports and felt that more people would like to read more about baseball than high school on Twitter.

The sports reporter, Nick, said:

People would retweet stories that I would write. That's when I started picking up [followers]. Definitely when I got a promotion to a college beat, which has a huge audience. It was like everything I wrote had to be tweeted out. The reporter said the culture of using social media at the newspaper has changed. (Author interview, February 13 2012).

Nick added, "I feel like I was late to it but the newspaper has been pretty accepting of using social media. They've been telling us to use Twitter for maybe a year. I had an account, I just didn't embrace it."

The metro reporter, Jake, said that it seems the sports department is well-versed in social media use because of "the high-profile type of reporters" that work on the desk.

\section{Basic Assumptions}

The assumptions of reporters in the newsroom that the editors do not have a social media strategy at this time potentially stems from the lack of articulation of such a plan by the editors. As mentioned earlier, the editor-in-chief and assistant managing editor for digital both have said that there is no written plan. Instead plans have been discussed at the highest levels of the newsroom. The social media editor also added that he felt an overarching plan for social media use would be pointless since the platforms are always changing.

An editorial writer, Thelma, said she was dismayed that more people in the newsroom were not using social media, specifically mentioning Twitter. She said, "I'm 
just shocked Twitter's not mandatory here at the newspaper...especially for the beat reporters, but it is strictly optional. I do not get that."

Thelma added that more needed to be done online because "the primary focus of social media is to drive people to our website. If they had more people on Twitter, we'd have more links and clicks. I don't know why they are not pushing that more."

The editors operate under the assumption that reporters do not want to do the additional work, while some reporters think that social media is another thing they have to do on a daily basis.

The editor-in-chief said:

Right now I do not see tremendous value in people who do not get it and understand it being out there on the front lines of this every day. We could certainly do training. We could have three training sessions in the newsroom, make it mandatory and make everyone do it. But, again, that just seems like we're shooting in the dark a little bit. (Author interview, March 1 2013).

He added that he thinks the newsroom needs to take a much more targeted approach to finding people who want to use these tools on a regular basis.

It is possible that The Metropolitan Post can reach more people via Twitter than any of the television stations that editors might consider competitors. The city's CBS affiliate has just over 24,000 followers on Twitter, 13,000 fewer than The Metropolitan Post's main Twitter account. But, on Facebook, The Metropolitan Post is no match for local television. While The Post boasts only 15,000 "likes" on Facebook, the local NBC affiliate is the closest to the newspaper with more than 30,000 likes. The Fox affiliate's Facebook likes are more than six times higher than The Metropolitan Post at 101,000. 
In the sports department, the deputy editor, Matt, said that reporters are encouraged to follow their competitors to make sure they aren't being scooped. If another organization has a story, reporters are expected to begin working on a story immediately.

"Some [stories] are worth taking a closer look at and you say to yourself 'Damn, we should have been doing that," Matt said. "You then have to ask is that worth pulling a reporter off a story to chase this one?" He said that social media also allows him and reporters to see more of other reporters' stories faster than ever before.

One sports reporter, Nick, said that Twitter helps keep him from being embarrassed and from being late to get a story. Before he began to use Twitter, Nick said “a story would come out and you'd just be 'Aw, man, I didn't have that' and everyone would have it for a full day. Now that rarely happens." He said that Twitter is "handy" for not getting beat on breaking sports stories. But if a competitor does beat them to a story, Nick said Twitter allows the sports reporters to quickly match with information of their own.

However, on the metro desk, there's a concern that sharing a story on social media will give it away to competing news sources. "I've known some reporters that will block the competition [on social media sites,]" Jake said. "To me, that's sad because there's so much information out there."

Another metro reporter, Karen, said that reporters and editors on the metro desk do not wish to match their competitors but instead choose to maintain secrecy about stories in progress, even within the office. She discussed a day in early February when reporters in the newsroom had a breaking news story late one afternoon, but held it until the next day for print. Her editor explained that the documents did not arrive until 7 p.m. 
and the audience on the web was dwindling. She said that was a good excuse, but that many mid-level editors were secretive about the story due to their fear that a television station would hear about the story and pick it up for a nightly newscast. She called the behavior "stone-age" but found her editor"s explanation encouraging.

Jake said that he has heard no conversations about how social media should be used in a breaking news situation. Of strategies for using social media in breaking news situations, "There have been no conversations at my level. I think there might have been some at the higher levels."

One reporter who does not use social media on a daily basis said she does not do so because she hasn't received guidance from the editors:

I do not use it to the full capability that I should because I do not know reporters here are encouraged to. I often ask questions, and it is more viewed as 'Oh, we have a team that does that. We have a social media editor and a reporter and certain people that do that.' I honestly do not feel like we're encouraged to do it. (Author interview, March 1 2013).

She also said that she is under the impression that editors only want columnists, not reporters, to be active on social media.

The reporter said she continues to ask people for help and training with social media and that she believes social media can be used for storytelling. This is something the editor-in-chief has also expressed interest in. But, the reporter said when she applied for a job in the mid-2000s, she was told by an editor that they would never put a story on the web until it's been in print. "We have come a long way since then," she said. "But, 
we're still playing catch up." The reporter said that in her opinion, reporters and editors at the top understand social media but feels there is a disconnect somewhere in the middle.

One political columnist said that his editors are interested in social media and that it is talked about in the newsroom, but there has never been a conversation about the strategic ways to use social media or to build an audience. Everything he learned about social media, he had to teach himself. He said he sees Facebook and Twitter as important but does not see it as much of a priority as getting a front page story and added that calling social media an afterthought would be understating its importance.

An assistant city editor said that he was neither encouraged nor discouraged by anyone to start using social media. As a tech reporter, he just picked it up on his own. Currently, his four political reporters that work in the state capitols all use Twitter on a regular basis. He said that growth in social media use in the office has been steady the past four years. He said if Twitter was not so easy to use, he wouldn't be able to utilize it. The editor added that the learning curve of social media is hard for people across the newsroom in tough times.

The only reason I can evangelize for Twitter is that it does not take much time to do. If it required much time, I'd be really skeptical. We're really stretched here. We've got less than half the staff we had five years ago and you really have to question is it worth it stopping and doing something other than the very single task ahead of you. I haven't seen any evidence that it is driving traffic and making money for us. (Author interview, March 6 2013).

The editor-in-chief shares the same concerns and questions the value of using social media to make money for the newspaper. A plus for him, however, is that he has 
access to data from other newspapers in the corporate structure, allowing his team to model a strategy after the success of something in another market. Recently, the digital editor and her team began using a new tool to understand social media's effect on website traffic and revenue.

The service, called Visual Revenue, keeps track of all of the newspaper's tweets and Facebook posts to determine the reach that each post has. The service allows the newspaper's staff to determine the optimal time to post links on social media. As the service learns about readers habits, it can recommend links to tweet and post to Facebook, and automatically post based on the metrics that will result in the highest traffic for the website.

Some reporters are not aware of any strategy whatsoever. One business reporter, John, said:

I've got to tell you. The [Post's] not given us much guidance. We get a lot of general comments like 'We'd like to see you do more on the web' but we've really not had any kind of organized, consistent approach to encouraging or guiding reporters on the use of social media. (Author interview, March 6 2013). But, he still maintains a presence on sites like Twitter and LinkedIn.

Besides the assumption that editors do not want to encourage social media use is the assumption that some middle managers (editors who have direct reports and report to another editor) have about the willingness of the newsroom's administrators to respond to change.

One video editor with the newspaper said he felt that higher-ups in the newsroom did not value the input of reporters and middle-management editors: 
There's very much a hierarchy that you have to follow," Daniel said. "So, you know, you've got to follow the steps in the chain of command. All I can do is encourage my bosses. If you vary from that, you find yourself in trouble.

Unfortunately, lots of good ideas go by the wayside because maybe the person you take an idea to does not run it up the chain. (Author interview, March 6 2013).

Some reporters want to see social media used by more people in the newsroom in hopes of attracting readers. Jake said, "I would like to see more reporters on social media. The reason being is that newspapers need to present a more social interchange." He described social media as a tool but not as "the tool" that a reporter needs. He said that more reporters need to be promoting themselves or sharing their work on social media and that reporters need to be tweeting from live events. He said the ideal way to use Twitter is to "hit the highlights, let people know that this story is coming up and will be published and then follow up when the story runs."

Over on the features desk, senior writer Greg said there are conversations about how to use social media to cover events but that they are casual. 'I don't think we've had any grand philosophical discussion about why we use Twitter or what we get out of Twitter."

Greg also added that he feels the newsroom managers are misguided in choosing how to lead change in social media. He said:

At one time, we had some young person who was our social media person who I didn't think was very smart. Sorry but our bosses weren't very smart about it. I 
don't think they knew what they wanted. They just sort of assumed if it's social media, you need someone young doing it. (Author interview, February 28 2013). But, the social media editor said that having more people using social media is not the answer. William said he sees no benefit in having every reporter on Twitter. That feeling stems from his experience with the tool. William said, "I have a Twitter account as the public editor and I abandoned it because it was feeling forced to try to come up with something every day."

However, on the sports desk, editors assume that their reporters are constantly plugged into social media. Matt, the deputy sports editor, said that he's constantly checking Twitter. Sometimes, he does it when he wakes up at night. He said, "I expect them [reporters,] within reason, to be doing the same thing because you never know what's happening out there."

The sports editor, James, said that the staff is trying to keep up with changing trends in social media. He said, "The model's changing. But, for what the model is right now, I think we're doing a pretty good job with it." To that end, social media use on the sports desk is not officially a requirement for the reporters, but the editor said it is "strongly encouraged to the point where I think it is an unwritten requirement."

James said he feels that his department is doing better in their use of social media because sports are discussed on a daily basis:

Sports just lend themselves to social media and to conversation. That's the thing. People like talking about a game or who played well in tennis last night. They're around the water cooler and doing that. Well, this is today's water cooler. (Author interview, February 28 2013). 
The newspaper's MLB reporter decided on his own to set up a question and answer session with readers on Twitter. Matt said editors realized the value that the crowdsourced questions could have to their web and print audiences not on Twitter. As a result, the Q\&A became a nearly daily staple of the print edition during spring training.

The college sports reporter, Nick, said that he keeps Twitter open throughout games that he is covering and tweets thoughts while working. "I'm a little surprised at how many people follow us on Twitter during games," Nick said, alluding to the secondscreen experience. He added, "You can see what other people are saying. It is really a new frontier. It is kind of crazy to imagine watching sports and covering sports without Twitter." Just like the sports editor comparing social media to a water cooler, this sports reporter thinks of Twitter during games as a bar.

But a reporter on the metro desk said that social media is not a priority for her editors. "Until everybody, especially middle managers, until they make it a priority, it won't be one," Karen said.

She said that she doesn't use social media because of this lack of priority. "I need them to tell me that 'I want you to tweet' because here, if you're told 'Oh, that's okay,' that means you should be doing this first," Karen said, referring to her editors wanting a print story before having an update on social media. She said social media has to be a priority on the metro desk or people just won't do the work. Even the reporters who can handle social media are feeling the stress of cutbacks in the newsroom. The multimedia reporter, Jake, said that his editors "need more of the written word than they need multimedia projects." 
Karen said she wants to learn about using social media, but said the tools are not regarded in the newsroom:

I have asked no less than four times... and I'm not trying to be negative because I love this place. But, I am honest, and I have asked no less than four times, 'Can [Jake] do a brown bag training session to tell us what to tweet or how to tweet.' It has not happened. Just the way he has treated it shows you how social media is treated at this place. (Author interview, March 12013 ).

But, training has been offered to the staff before. Karen said the newspaper brought in a speaker from Freedom Forum in Nashville to talk about social media use in breaking news in 2012, but that no editors showed up to the event. Karen said:

If it's not a priority to them, it's just is not going to become a reality. It's really sad for me because I think our paper is truly right up there with other papers, but we're going to lag behind (Author interview, March 1 2013).

An editorial writer, Roger, described conversations about social media in the newsroom as "lip service." "The Twitter presence in the newsroom is almost nothing," Roger said. He said there are no conversations going on during the day about the news, adding “I'm sorry, Twitter's not that hard." He said that social media should be used for promotion of stories and engagement with readers. "I don't think this newsroom takes social media as, one, seriously as it should and, two, as seriously as it could to promote a more dynamic dialogue with readers," Roger said.

"All of the editors downstairs could be tweeting," Roger said. "Anything to get the brand out there or 'Hey, this is what you'll be reading in the [Post] tomorrow." Those are the same things that the editor-in-chief said he wants out of social media: 
What has changed is our strategic approach to social media. That has evolved over the years. I think that when social media - when the first wave crashed against the shore - we were looking at those things as more of as promotional vehicles - ways to build our brand and promote our content. Those pieces are still true but the industry sees it as a more legitimate way to tell stories. (Author interview, March 1 2013).

The sports staff sees social media as more than just brand building and promotion. They see it as a way to build stories, engage with readers and tell stories they may have not known about. But, they recognize that it has limits.

One hurdle that the editors and reporters face when tweeting about sports are the regulations set by sporting agencies. James said:

As much as the NCAA, the NFL and MLB want to control you, they're going to. So, we're fighting battles from time to time about how much we can tweet during a game. I personally do not see the value of tweeting every play during a game. (Author interview, February 28 2013).

On that point, James noted that people get play-by-play on television or in other places online. He said he feels that people on social media are looking for milestone events that the reporter can provide insight with along the way throughout the game. Furthermore, he said that he stresses to reporters the importance of the "second-screen" experience, noting that he does not even watch games the way he used to thanks to social media.

The deputy sports editor, Matt, described the way his reporters are advised to use social media as a "rule of thirds.": 
A third of it is stuff you're doing on your beat," Matt said. "Another third is tweeting other good stories and opinions from other reporters that may cover the same thing you do. And the final third is your opinions that have an entertainment aspect to it. (Author interview, March 1 2013).

As for the overall future of social media use in the newsroom, the social media editor, William, said he doesn't foresee many changes in the near future. He said the only shifts would be in codifying social media use by telling people how to use it. "Newspapers are so decentralized anyway," William said. "There's very little that is directed from above. I don't see there being any specific changes that we basically don't make ourselves here."

William's comments on the future of social media contradict the earlier statements of Janet, the previous staff member to have the role of social media editor. She said that the newspaper had trusted corporate to do this "since they said they would do it." As for now, the only guidance given to reporters is to look at the newspaper's code of ethics for information on how to best conduct themselves online.

His comments on the "decentralized" newspaper also help explain how social media can be regarded differently, even in different departments of the same newsroom.

These competing assumptions are potentially detrimental to the organization. The assumptions might also prevent any change to the newsroom's culture toward social media use.

\section{Limitations and Implications}

As previously mentioned, it is important to note that during my observation period, the newsroom was undergoing a major renovation. Some staff members told me 
that they had not worked in the main newsroom for more than a year. The work on the currently occupied half of the newsroom was completed in 2012. It is possible that once the entire newsroom is brought together in one space again that communication will improve among editors at the top, assigning editors in the middle and reporters.

One limitation was not being able to interview additional editors and reporters for this study due to scheduling conflicts or simple refusal to participate in the research. One assistant city editor refused to be interviewed because he said he had nothing to do with social media or his reporters using social media. One of the online producers provided a similar refusal, saying that while he worked daily with updating content on the website, he did not have much use for social media. Sports columnists were not interviewed due to the nature of their time in the office. During the entire research period, neither of the sports columnists were available for interviews.

Another limitation I experienced during my observation was being hindered to make it into the newsroom during a major winter storm. I missed one scheduled day of observation and instead watched social media and the newspaper's website throughout the day to stay informed of what was going on. The next day, I spoke with reporters and editors to fill in any gaps in knowledge.

\section{Researcher's Perspective}

When I first arrived to the newsroom in February, I sensed that the editor-in-chief had hesitations about my presence there. Many staff members, especially the core group of staff members in "The Octagon" as well as the social media editor, quickly warmed up to my presence and would freely talk about the newsroom. They would also engage me in personal conversation. I carried on conversations with the staff because I felt it made 
them more comfortable to talk to me in an interview and to be more open in their conversations.

In the first day or so of the observation period, I would retreat to a couch in the break area to compile my notes. The editor-in-chief approached me about this and offered to locate a desk for me to use during the duration of the research. It was this moment that I realized the members of the administration had become comfortable with me in the newsroom. As a result, my access to people in the newsroom and around the newspaper's office was much easier. 


\section{Conclusion}

At The Metropolitan Post, I found that social media use is an afterthought by many reporters and editors. Only in the sports department is social media considered a tool that should be used daily and often. In other parts of the newsroom, there is a resistance to even using social media. There is a sense of ambivalence toward the creation of a social media policy and a strategy for how to best use the tools. This is evidenced by the failure to produce written versions of either a social media policy or strategy that can be shared with all employees of the newspaper.

As I observed the newsroom on the night of the business explosion, there were clear signs that social media is an afterthought by many at the newspaper, especially on the metro desk. The digital editor was left to run around from desk to desk to collect information from reporters who were taking in information from other reporters on the scene. In the evening's news rundown discussing the next day's coverage, the digital editor said there was no mention of social media. However, there is also a lack of unity on how to best move forward with strategies, even within the digital team. On the morning after the business explosion, William began discussing the idea of a phone tree with Melissa. Melissa grabbed her laptop and promptly turned around to look for photos for using online. One of the online editors said to William, "She does that all the time."

Schein's three levels of analysis of organizational culture provided a useful framework to examine the role of social media in this newsroom. Artifacts included the newsroom's current renovation which has departments scattered all throughout the building. Values included those traditional journalistic values, including source 
development, deadline reporting, serving as a watchdog, alongside values that come with social media: promotion, engagement and a sense of community. Assumptions in the newsroom, which appear to provide the most peril to cultural change, are the conflicting beliefs on the value of social media. Some reporters see it as a useful tool - asking for training on the tools and wondering why it is not mandatory - while editors see it as something that should not be overstated.

In answering RQ1, "How does social media change the way that reporters and editors distribute news to consumers?" I concluded that the sports department at the newspaper has undergone the greatest changes in content delivery via social media. Reporters in that department are urged to break news on Twitter first instead of waiting to break news in print the next day. The newspaper's business editor, however, does not see social media as a tool for breaking news but only for promoting content. The editor-inchief has a grand vision of using Twitter to tell a narrative story piece-by-piece but others, including the digital editor, don't share the vision.

RQ2 asked "How has newsroom culture changed to adapt to social media use as a journalistic tool?" There is a short answer to this. The culture hasn't changed throughout the newsroom but the sports department seems to have adapted well. The deputy managing editor of the department and a reporter attributed the change to the arrival of a news sports editor in late 2010 as the catalyst for social media use. The sports editor said that the key to getting his reporters to use Twitter was to have them realize that news could be broken on social media. Also, reporters and editors on the sports desk believe in social media as a useful tool. 
"From the moment James came in 2010," Matt said. "There was an instant upgrade in terms of attention to digital." One of those upgrades, Matt said, was a renewed presence on Twitter. Throughout the newsroom, in formal interviews and in casual conversations, staff members always mentioned the work of Sports.

But on the business and metro desks, there are mixed feelings about social media use. Editors say they understand the importance of social media as a journalistic tool but have a hard time determining the value of social media. The editor-in-chief said the main goal of social media use for the newspaper is to get more people to read the stories that reporters are writing. With the addition of the Visual Revenue service, the newspaper's administration is moving toward a culture where social media is not seen as an engagement tool. Instead, social media use is driven by potential profit and not subsections of the newspaper's audience.

Future research is needed to explore the effect of automatic social media posts on reader engagement. It is important to understand whether readers are more likely to interact with automatic posts or those written manually, which may include a question or other call to action.

RQ3 asked "Which group of stakeholders has the most influence in directing a company's social media policy?" In the case of The Metropolitan Post, it is unclear who makes the decisions. The newspaper's original social media editor, Janet, said that the newspaper has been waiting for two years for the corporate organization to produce these documents. The current social media editor said he is working with a corporate committee to produce a social media policy and strategy by the end of this year, but conceded that change would likely come at the newsroom level. 
However, no planning is happening with social media in the newsroom due to other priorities. The assistant managing editor for digital, who began working with the newspaper in late 2012, said that her bosses have tasked her with working on a website redesign and developing an application for tablet devices. She said that there is simply no time to work on anything dealing with social media. But, the editor-in-chief, digital editor and social media editor say they have a strategy, but that it's not written down. Reporters interviewed were not even aware of any plans that managers had for social media use. "We do not have a social media policy," Karen, a metro reporter, said. "If we do, it's a secret. To me that is just unacceptable, especially when we are so good at what we do." Schein writes that "most operations involve interdependencies between separate elements of the process; hence operators must be able to work as a collaborative team in which communication openness, mutual trust and commitment are highly valued" (2010b, 44). Through my observation in the newsroom of the Metropolitan Post and interviews with reporters and editors there, one thing instantly became clear. The newspaper's editors and reporters are not on the same page when it comes to what the strategy is for social media use in the newsroom.

The reporters' lack of knowledge that the social media strategy exists is a sign that there is a major disconnect between the editor-in-chief and the reporters that work in each department. The editor-in-chief has a vision that social media is a tool that can draw in more readers and ultimately more revenue. Mid-level editors have embraced the digital side of reporting but have trouble realizing the connection between social media and traditional media. 
In conclusion, changing the newsroom's culture toward social media is going to be a rocky process. The biggest concerns raised by my observation and interviews are that the values of using social media in journalism including quick engagement with members of the community, the crowdsourcing of information for stories and ease of access to reporters on a daily basis are conflicting with long-held tenets of journalism. These include digging up hard-to-find information, breaking stories in a print platform and being a watchdog for the community. Some editors at The Metropolitan Post believe that both ways of doing things cannot survive together. Until all departments treat social media as the sports department does, I believe that social media is never going to be embraced by staff members at this newspaper. 
Appendix 1. Organizational Chart, The Metropolitan Post

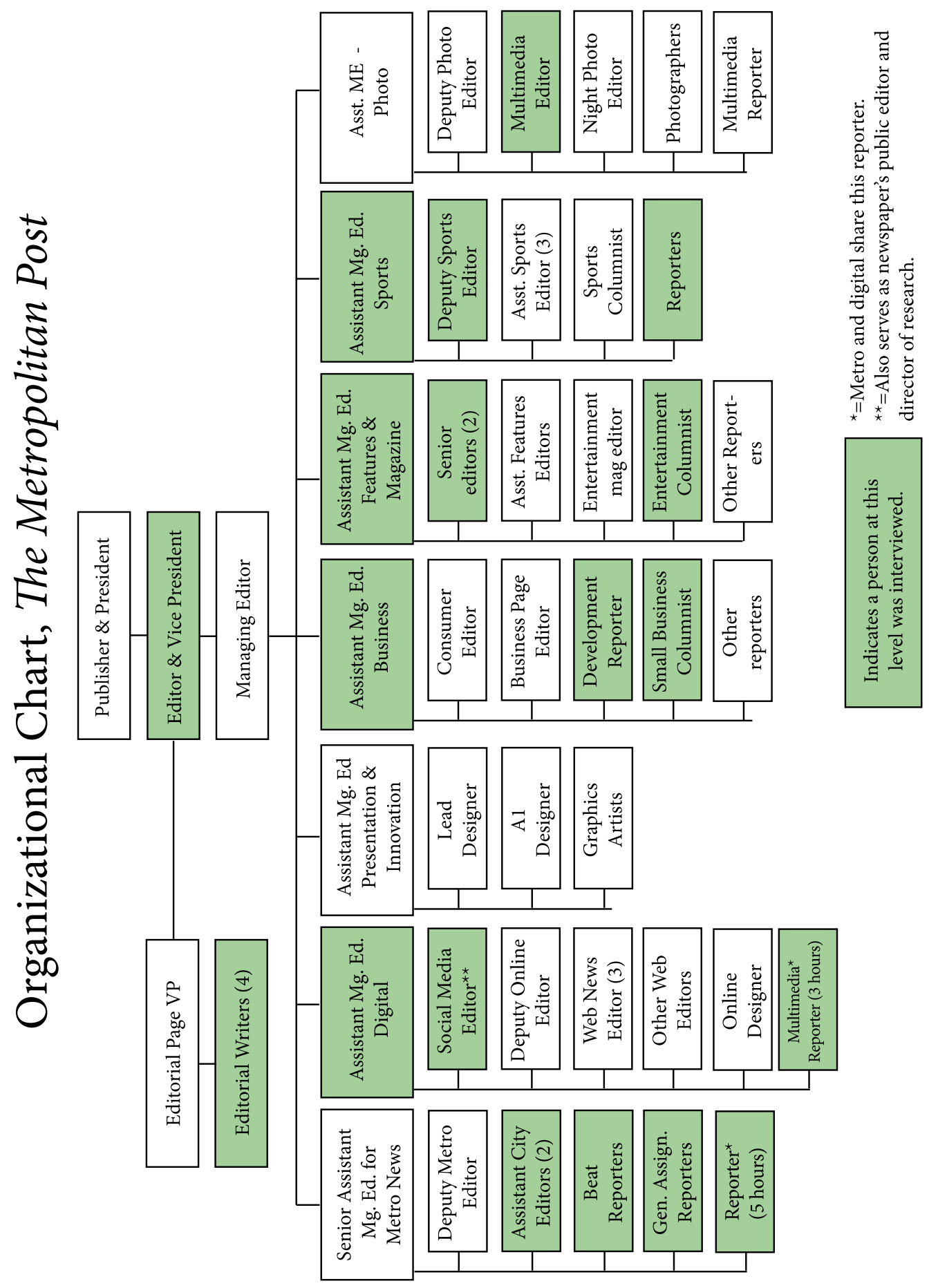


Appendix 2. Interview Subjects

\begin{tabular}{|l|l|l|}
\hline Pseudonym & Title & Department \\
\hline "Thelma" & Writer & Opinion \\
\hline "William" & Social Media Editor & Digital \\
\hline "Janet" & AME & Features \\
\hline "Nick" & Reporter & Sports \\
\hline "James" & AME & Sports \\
\hline "Matt" & Deputy Editor & Sports \\
\hline "Richard" & Editor-in-Chief & \\
\hline "Greg" & Editor/Writer & Features \\
\hline "Jake" & Reporter & Digital/Metro \\
\hline "Sarah" & Reporter & Business \\
\hline "Thomas" & Reporter/Editor & Metro \\
\hline "Ronald" & AME & Business \\
\hline "Alexandria" & Columnist & Features \\
\hline "Roger" & Writer & Opinion \\
\hline "John" & Reporter & Digital \\
\hline "Karen" & Reporter \\
\hline "Melissa" & AME & \\
\hline "Daniel" & Video Editor & Photo \\
\hline "David" & Polics Reporter & Metro \\
\hline
\end{tabular}




\section{References}

Ahmad, A.N. (2010). Is twitter a useful tool for journalists? Journal of Media Practice, 11(2), 145-55

Alliance for Audited Media. (2013). "Media Intelligence Center." http://www.auditedmedia.com.

Associated Press. (1999). "Newspaper to publish online only.” July 29. http://bit.ly/OKTda7

Berger, A.A. (2011). Media and communication research methods: An introduction to qualitative and quantitative approaches. 2 nd ed. Thousand Oaks, Calif.: Sage Publications

Briggs, M. (2012). Journalism Next: A practical guide to digital reporting and publishing. Washington, D.C.: CQ Press.

Buttry, S. (2012). “Denver Post staffers' \#theatershooting coverage demonstrates Twitter breaking news techniques." http://stevebuttry.wordpress.com/2012/07/23/denverpost-staffers-theatershooting-coverage-demonstrates-twitter-breaking-newstechniques/

Deuze, M. (2003). "The web and its journalisms: Considering the consequences of different types of newsmedia online." New Media Society, 5(2), 203-20.

Dupagne, M., \& Garrison, B. (2006). The meaning and influence of convergence: A qualitative case study of newsroom work at the Tampa news center." Journalism Studies, 7(6), 237-255.

Farhi, P. (2009). The twitter explosion. American Journalism Review. 31(3), 26-31

Gade, P.J. (2004). Newspapers and organizational development: Management and journalist perceptions of newsroom cultural change." Journalism \& Communication Monographs, 6(3), 3-55.

Gade, P.J. (2008). Journalism guardians in a time of great change: Newspaper editors' perceived influence in integrated news organizations. Journalism \& Mass Communication Quarterly, 85(2), 371-92. 
Gade, P.J., \& Perry, E.L. (2003). Changing the newsroom culture: A four-year case study of organizational development at The St. Louis Post-Dispatch." Journalism \& Mass Communication Quarterly, 80(2), 327-47.

Giles, R.H. (1987). Newsroom management: A guide to theory and practice. Indianapolis: R.J. Berg \& Co., Inc.

Greer, J.D., \& Yan, Y. (2011). Newspapers connect with readers through multiple digital tools. Newspaper Research Journal, 32(4), 83-97.

Hermida, A. (2010). Twittering the news. Journalism Practice, 4(3), 297-308.

Hu, M. et al. (2012). Breaking news on twitter" Paper presented at SIGCHI Conference on Human Factors in Computer Systems, Austin, Texas, May 5 - 10.

Luis Small, M. (2009). 'How many cases do I need?': On science and the logic of case selection in field-based research." Ethnography, 10(1), 5-38.

Lysak, S.,Cremeda, M., \& Wolf, J. (2012). Facebook and twitter in the newsroom: How and why local television news is getting social with viewers?" Electronic News, 6, 187-207.

Mayer, J. (2011.) A culture of audience engagement in the news industry" Master's thesis, University of Missouri - Columbia.

Noor, K.B.M. (2008). Case study: A strategic research methodology." American Journal of Applied Sciences, 5(11), 1602-04.

Pavlik, J. (2000). The impact of technology on journalism." Journalism Studies, 1(2), 229-37.

Robinson, S. (2011). Convergence crises: News work and news space in the digitally transforming newsroom. Journal of Communication, 61, 1122-41.

Roberts, M. (2009). Rocky mountain news: Final edition" [Video]. Accessed November 15. http://www.rockymountainnews.com.

Rosenstiel, T., Jurkowitz, M., \& Ji, H. (2012). The search for a new business model: How newspapers are faring trying to build digital revenue." Pew Research Center. http://www.journalism.org/node/28629

Schramm, W. (1971). Notes on case studies of instructional media projects." Working Paper for the Academy for Educational Development, Washington, D.C. 
Schein, E. (2010a). Organizational culture and leadership. 4th. ed. San Francisco, Calif.: Jossey-Base Publishers

Schein, E. (2010b). Three cultures of management: The key to organizational learning." "Glocal" Working: Living and working across the world with cultural intelligence. Milan, Italy: FrancoAngeli.

Schultz, T. (1999). Interactive options in online journalism: A content analysis of 100 U.S. newspapers." Journal of Computer-Mediated Communication, 5(1). doi:10.1111/j.1083-6101.1999.tb00331.x.

Stake, R.E. (2011). The Art of Case Study Research. Thousand Oaks, Calif.: Sage Publications.

Yin, R.K. (2009). Case Study Research: Design and Methods. 4th Ed. Los Angeles, Calif.: Sage Publications 